\title{
Prediction of the lifetime of droplets emitted from mechanical cooling towers by numerical investigation
}

\author{
F. Sánchez a, A.S. Kaiser a, B. Zamora a, J. Ruiz b, M. Lucas b \\ a, Departamento de Ingeniería Térmica y de Fluidos, Universidad Politécnica de Cartagena, Dr. Fleming, s/n, 30202 Cartagena, Spain \\ b, Departamento de Ingeniería de Sistemas Industriales, Universidad Miguel Hernández, Avda. de la Universidad, s/n, 03202 Elche, Spain \\ Abstract
}

A numerical modelling capable to simulate the drift and the evaporation of water droplets emitted by a mechanical cooling tower in an urban area is presented. The model is based on a real mechanical draft cooling tower situated in the surroundings of the Miguel Hernández University (Elche, Spain). An experimental study of the deposition of droplets from the cooling tower is done in order to validate the numerical modelling. This study is performed by means of the water sensitive papers technique. A biharmonic interpolation is used for obtaining the total deposition on the floor. A total of 14 cases, everyone with different atmospheric conditions, have been simulated and experimentally validated. An analytical model for the droplets lifetime prediction is validated with the results obtained from the numerical modelling. The present study shows the influence of the atmospheric and droplets conditions in the droplets lifetime, providing useful information to analyse the spread of contaminants or bacteria inside the droplets released from the cooling tower.

Keywords

Cooling tower; numerical modelling; droplet evaporation; droplet lifetime.

1. Introduction

Mechanical cooling towers are one of the most efficient evaporative heat transfer devices; clear proof of it is that they are the most used heat removal systems. However, cooling tower could present an important problem: colonies of bacteria, such as Legionella, can grow inside the towers. These bacteria can spread to the atmosphere through the water droplets emitted from the cooling towers, causing legionellosis or Legionnaries' disease in people, due to the inhalation of mist droplets containing the bacteria [1]. Hence, local public health authorities introduced policies to replace cooling towers by other less efficient systems (for example, air-cooled refrigerant systems). That replacement contributes to increasing energy consumption and thus to contribute the climate change.

The principle of operation of most of the mechanical cooling towers requires spraying water over a heat transfer surface across or through which a stream of air is passing. Water droplets are incorporated into the air stream. This mix of warm air and water droplets leave the cooling tower (drift) and incorporate into the atmospheric air. An analysis of the cooling tower drift could help to control the areas susceptible of containing Legionella in a case on an outbreak: the distance from the tower that the emitted droplets reach can be employed for estimating the affected area. This information would be also useful to find the source of the bacteria in the outbreaks with unknown source. Computational Fluids Dynamics (CFD) is a suitable tool for estimating drift, droplet evaporation and deposition in cooling towers zones (Takata et al. [2], Riddle et al. [3]). In the work of Lucas et al. [4], a study of the influence of psychometric ambient conditions on cooling tower drift is carried out by means of CFD tools. Meroney [5] presented 
numerical results for the cooling tower dispersion and drift downwind the cooling tower. Lu et al. [6] studied the influence of the wind direction in the performance of a natural draft cooling tower. Consuegro et al. [7] analysed the drift and deposition of droplets as a function of atmospheric conditions, as well as the influence of the surrounding buildings on the results of the modelling. The above-mentioned works study the cooling tower drift and analyse the influence of the atmospheric conditions. But cooling tower drift depends simultaneously on the atmospheric conditions and the distribution of droplet sizes. A suitable way to consider both variables (atmospheric conditions and droplet size distribution) is by means of the analysis of droplets lifetime as a function of the atmospheric conditions and the droplets size. The area of influence of the cooling tower is determined by the distance covered by the water droplet (where the bacteria travel), which depends on the lifetime of the droplet. The higher their lifetimes are, the longer distances they reach. Several authors have studied the lifetime of sessile drops (Hu and Liu [8], Girard et al. [9], among others). Holterman [10] developed an analytical model to estimate the lifetime of a droplet falling down at its sedimentation velocity in still air. However, the mentioned works about droplets lifetime analyse the evaporation of a droplet under controlled conditions, while in a cooling tower, there is a mix of the warm air with the atmospheric air (each one with different temperature, relative humidity and velocity), and each droplet has a different diameter. Lifetime of the droplets depends on the atmospheric conditions and the conditions of the emitted droplets (temperature, size). An experimental study of the droplets lifetime in a real urban environment would present some sources of measurement uncertainty, due to the necessity of finding the exact moment when the droplets, with a few microns of diameter, finish the evaporation. For this reason, a CFD numerical modelling is developed for calculating the lifetime of the particles in an urban environment, under different atmospheric and droplets conditions.

The aim of this work is the prediction of the lifetime of droplets emitted from mechanical cooling towers. For this, a study of the validity of the analytical droplet lifetime model of Holterman [10] for the droplets emitted by a cooling tower located in an urban environment is carried out. The Holterman's model was developed assuming that the droplet is falling down at sedimentation velocity (neglecting horizontal relative velocity with the air), with the wet bulb temperature of the air. Nevertheless, in a cooling tower the conditions are not so simple. The mix of air and droplets arise from the cooling tower with vertical velocity. This mix incorporates into the atmospheric air, in a very turbulent process, changing the temperatures and velocities of the air and the droplets. According to the experimental measures taken in a cooling tower by means of hidrosensible paper technique (explained in next section). The droplets emitted by the cooling tower cover a wide range of sizes; the smallest ones have a few microns, while the biggest ones have diameters close to one millimetre. This wide range of size allows studying the validity of the Holterman's model for the different sizes of particles. The prediction of the lifetime of the particles as a function of the atmospheric conditions and the size of the droplets emitted by the cooling tower allows knowing which days the atmosphere is potentially dangerous in case of an outbreak of Legionella. The knowledge of the lifetime of the droplets would be also useful to narrow the area influenced by the cooling tower, where the droplets with Legionella could drop.

2. Experimental procedure

An experimental study of the behaviour of a pilot mechanical draft tower is carried out. Near the pilot cooling tower, a meteorological tower equipped with data logger is used to obtain the 
ambient conditions (see Fig. 1). Profiles of wind velocity, temperature and humidity, measured through the meteorological tower, are used as boundary conditions for the numerical modelling.

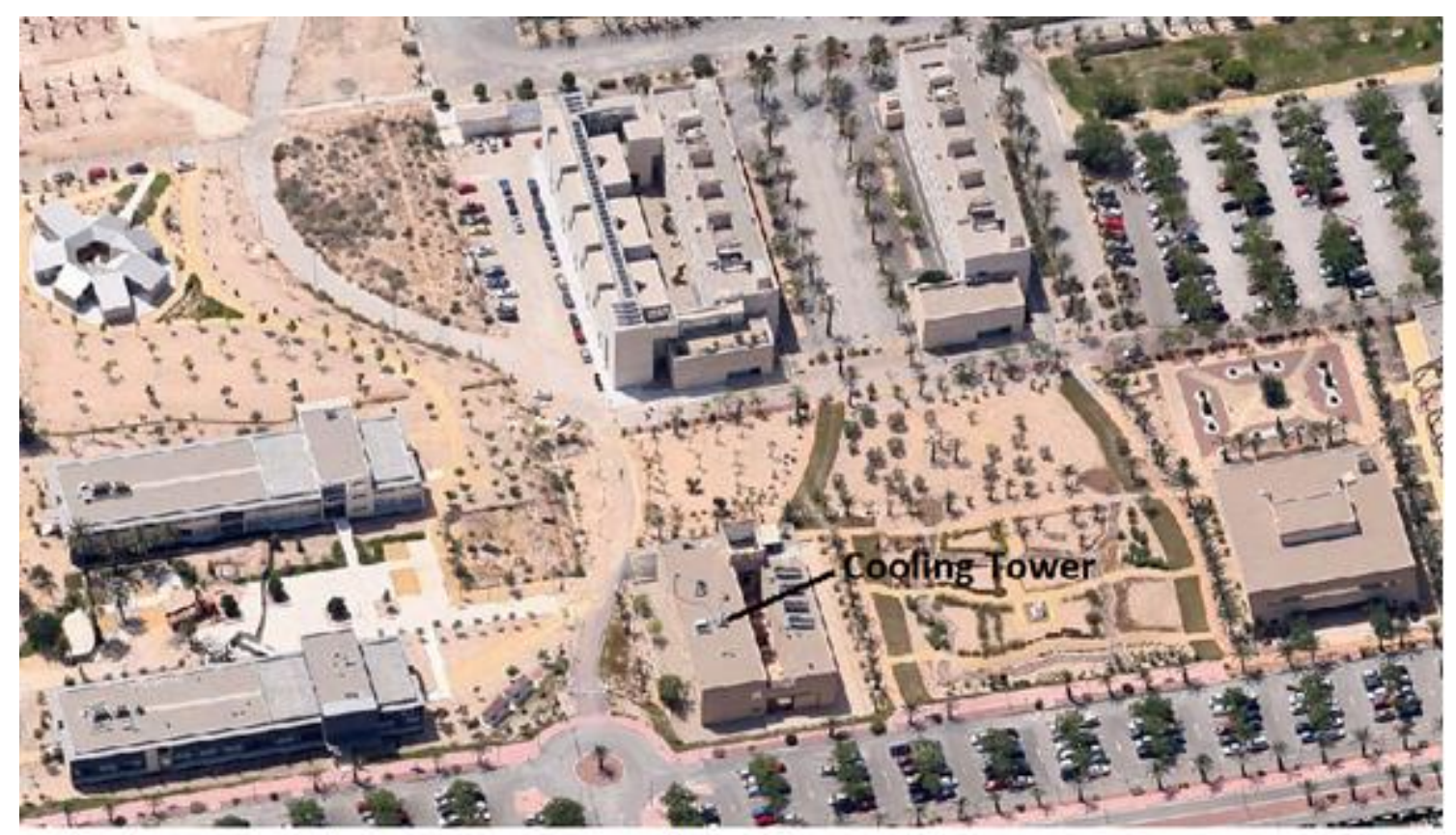

a)

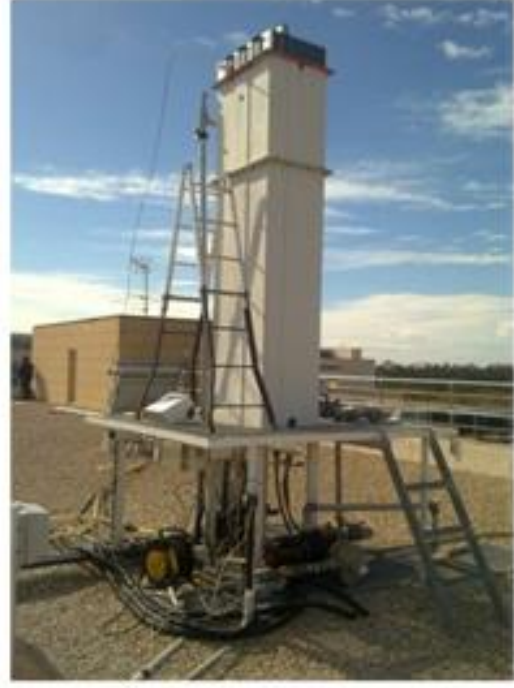

b)

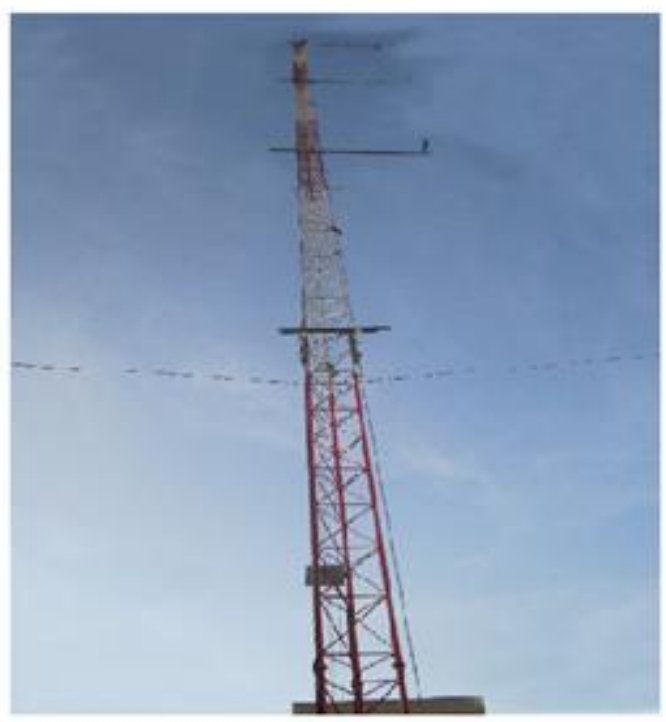

c)

Figure 1. a) Real urban environment studied in this work. b) Pilot mechanical cooling tower. c) Meteorological tower.

For each case, two experimental tests (emission test and deposition test) are performed for obtaining the water droplets characteristics (mass of water released, droplets size distribution and droplets temperature, among others), as well as the deposition around the cooling tower. The water droplets characteristics are used as boundary conditions of the numerical modelling, while the deposition around the cooling tower is used to validate the numerical modelling.

\subsection{Description of the experimental installation}

This work presents an experimental study of a pilot cooling tower located in the Miguel Hernández University (Elche, Spain). The cooling tower is on the top of a building of $13 \mathrm{~m}$ height. 
There are other six buildings around the cooling tower building, with heights ranging from 9 to $21 \mathrm{~m}$. The mechanical draft cooling tower has $2.6 \mathrm{~m}$ height and a cross-section $0.7 \times 0.55 \mathrm{~m}$. The cooling tower is equipped to measure the temperature and relative humidity of the air released from the cooling tower, as well as the mass flow rate of water released. The droplets temperature is assumed to be the wet bulb temperature of the air released from the cooling tower. The conditions of the atmospheric air are obtained through a meteorological tower situated near the cooling tower building, which provides measurements of wind velocity, wind direction, air temperature, air humidity and atmospheric pressure at three different heights (15 $\mathrm{m}, 25 \mathrm{~m}$ and $40 \mathrm{~m}$ ). The measurements at different height permit us generating profiles for the wind velocity and air temperature. The physical principia of the sensors used during the experiment and the specifications of the measuring devices are shown in Table 1.

\begin{tabular}{|c|c|c|c|c|c|}
\hline Parameter & Model & Sensor & Range & Accuracy & Output \\
\hline Air temperature ${ }^{1}$ & $E+E(E E 20-F T 6 B 511)$ & Capacitive sensor & -20 to $80^{\circ} \mathrm{C}$ & $\pm 0.3^{\circ} \mathrm{C}$ & 4-20 mA \\
\hline Air humidity ${ }^{1}$ & $E+E(E E 20-F T 6 B 511)$ & Capacitive sensor & 0 to $100 \% \mathrm{HR}$ & $\pm 2 \%$ & $4-20 \mathrm{~mA}$ \\
\hline Water flow rate ${ }^{1}$ & Krohne Optiflux 2000 & Electromagnetic & DN 25 to 150 & $\pm 0.3 \mathrm{~m} . \mathrm{v}$ & $4-20 \mathrm{~mA}$ \\
\hline Water temperature ${ }^{1}$ & Desin & Pt 100 type RTD & -200 to $600 \circ \mathrm{C}$ & 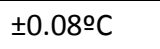 & 4 wires \\
\hline Air temperature ${ }^{2}$ & Geonica STH-5031 & Resistor (RTD) & -30 to $70 \circ \mathrm{C}$ & $\pm 0,1^{\circ} \mathrm{C}$ & 4 wires \\
\hline Air humidity ${ }^{2}$ & Geonica STH-5031 & Capacitive polymer & 0 to $100 \% \mathrm{HR}$ & $\pm 3 \%$ & $0-1 \mathrm{~V}$ \\
\hline Wind velocity ${ }^{2}$ & Geonica 3002L & Cup anemometer & 0 to $50 \mathrm{~m} / \mathrm{s}$ & $\pm 0,5 \mathrm{~m} / \mathrm{s}$ & 4-20 mA \\
\hline Wind direction ${ }^{2}$ & Geonica 3002L & Vane & 0 to $360^{\circ}$ & $\pm 0,5^{\circ}$ & $4-20 \mathrm{~mA}$ \\
\hline Ambient pressure ${ }^{2}$ & Geonica 61302V & Abs. pressure sensor & 500 to $1100 \mathrm{hPa}$ & $\pm 0,2 \mathrm{hPa}$ & $0-5 \mathrm{~V}$ \\
\hline
\end{tabular}

Table 1. Sensors devices specifications. (1) indicates that the devices belong to the cooling tower. (2) indicates that the devices are located in the meteorological tower.

All data were monitored with an Agilent 34970A Data-Acquisition Unit. A specific software was written and compiled for the system in HP BenchLink Data Logger Software, supporting up to 36 inputs, with 16 bits $A / D, 9600$ bauds transmission speed and programmable gain for individual channels.

\subsection{Description of the experimental methodology}

As previously mentioned, the numerical modelling is validated by several experimental tests. These tests are carried out in order to determine the emission of droplets from the cooling tower and the deposition of them on the floor, by means of the hidrosensible paper technique [11]. Sensitive papers, which are chemically treated, are placed on the floor in the vicinity of the tower. When a water droplet impacts on the paper, a blue stain on the yellow background appears. By means of a digital processing of the papers, a relationship between the sizes of the stains and the diameters of the droplets can be obtained. Summing all the droplets on each paper, the total mass of water deposited on the paper can be determined. One important limitation of hydro sensible paper technique is the fact that two or more droplets could land on the same spot. In order to avoid this problem, before each emission test, a trial test was performed in order to decide the optimal exposure time of the papers (the test duration). The time was considered as optimal when obtaining the maximum number of stains without overlapping between droplets.

The aim of the emission test is to know the distribution of sizes of the droplets released from the tower. Nine papers are located on the tower exit. The cooling system is activated, and the 
wet air with water droplets arises from the cooling tower, impacting on the papers and leaving the stains on them. The temperature and humidity of the released air is measured, as well as the mass flow rate of water. The appropriate processing of the papers leads to obtain the size distribution of the droplets; as expected, the distribution tends to a Rosin-Rammler's one (eq. 16). Two parameters are necessary for defining this distribution: the mean diameter $\overline{D_{p}}$ and the size distribution parameter $n . \overline{D_{p}}$ is obtained from the measured cumulative mass distribution at the diameter where the cumulative mass distribution is $1-\mathrm{e}^{-1}$; while $\mathrm{n}$ is determined by isolating the variable $n$ in eq.(16) for each drop diameter interval. The information obtained from the emission test is used for defining the size distribution of the droplets and the total amount of water released by the cooling tower in the numerical modelling. The repeatability of the emission test has been evaluated by means of the comparison of the total amount of water trapped by the sensitive papers in each case. In spite of being have done in different days, all the emission tests have been done in similar conditions, as the atmospheric conditions do not have influence on the test. The maximum variation among the total amount of water trapped by the sensitive papers in each test is less than $5 \%$.

The aim of the deposition test is to know the water deposition on some points of the floor. A total of 20 sensitive papers are located on the floor around the cooling tower. They are arranged in lines forming different angles (counter clockwise) with respect to the south-north direction, at distances from the tower ranging from 3 to $21 \mathrm{~m}$. The cooling system of the tower is activated, and some of the water droplets released from the tower deposited on the papers. The test lasts 30 minutes. For that period of time, some atmospheric variables (wind velocity, wind direction, air temperature and air humidity) are taken by the meteorological tower as well as by the meteorological station. After, the papers are processed and they show the water deposition on 20 points of the floor. The deposition is used for validating the numerical modelling, while the mean atmospheric conditions are used as boundary conditions of the numerical simulation. It is very complicate to evaluate repeatability of the measurements in the deposition test. The results of the deposition test depend on the atmospheric conditions, and it is not very likely that the atmospheric conditions do not change during two following deposition tests (each one lasts 30 minutes). Deposition test of Case 9 (see table 3) was repeated once in order to analyse the repeatability. In spite of possible changes in the atmospheric conditions, the variation between the total amount of water deposited on the papers in both cases was $7.2 \%$.

3. Numerical procedure

\subsection{Physical domain}

The 3D urban domain used in this work has a length of $800 \mathrm{~m}$, a width of $800 \mathrm{~m}$, and a height of $400 \mathrm{~m}$. The domain reproduces the area of the Miguel Hernandez University (Elche, Spain) where the pilot cooling tower is placed. The domain contains the seven buildings that exist in the real area, including the building in which the cooling tower is installed. The domain was generated in two different regions. The internal region is a cylinder with a $260 \mathrm{~m}$ radius, and it contains the seven buildings. The external region is an $800 \times 800 \times 400 \mathrm{~m}$ hexahedron with a hole where the internal region is located. The aim of this division of the domain is to simulate any wind direction, with a simple twist of the internal region. In this way, the wind goes into the domain perpendicular to the inlet face, avoiding some convergence problems encountered when the wind was no perpendicular to the inlet plane of the domain (Fig. 2). 


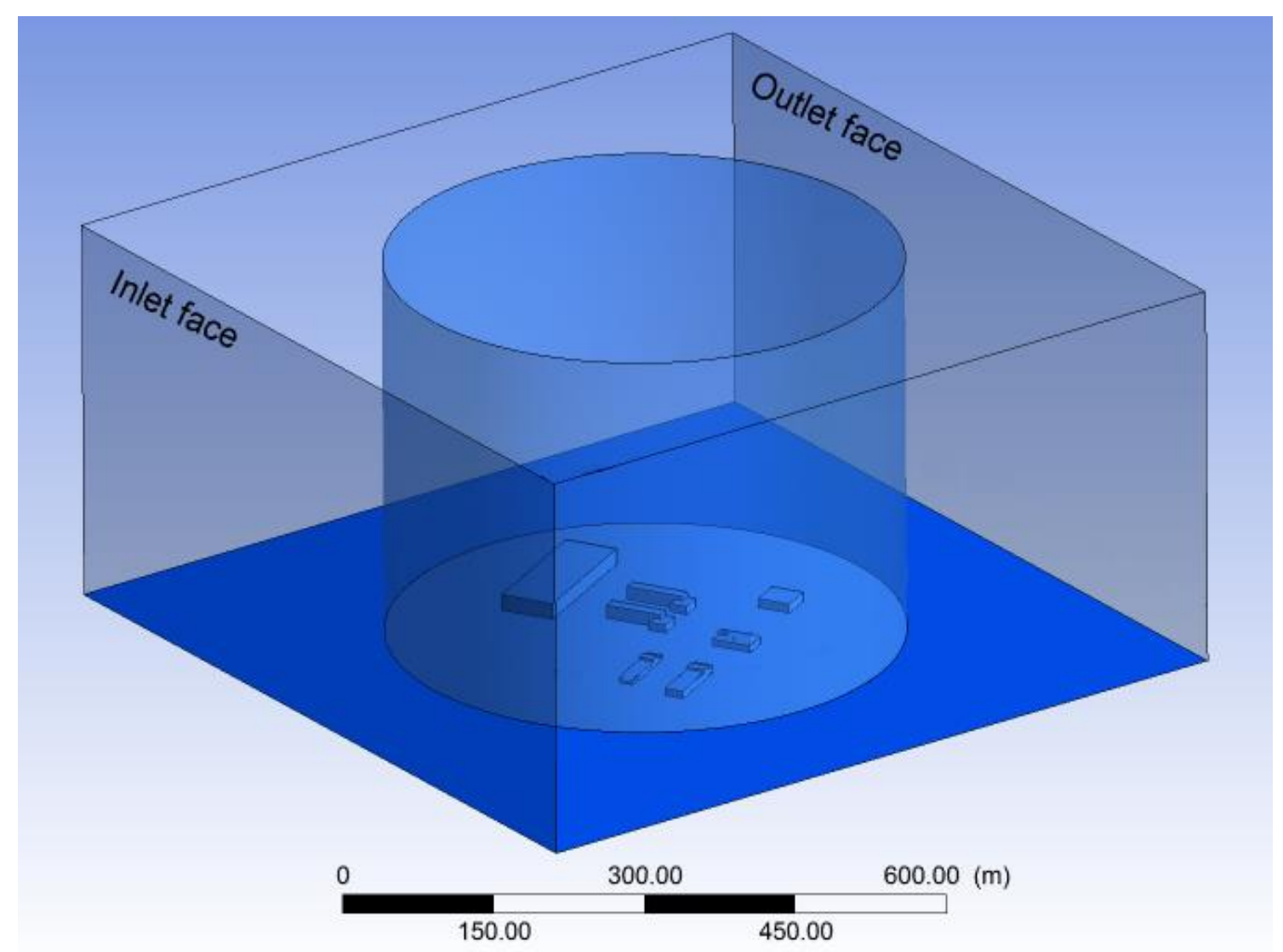

Figure 2. Geometry of the problem. The central region is twisted depending on the wind direction.

In order to justify the size of the physical domain chosen to perform the simulation, several computational domains have been considered for studying the influence of the size of the domain, finding that the hexahedron with $800 \times 800 \times 400 \mathrm{~m}$ gives accurate results, with independence of the domain size (see Consuegro et al. [7]).

\subsection{Governing equations}

An Eulerian-Lagragian model is employed for simulating the two phases involved in the problem. The continuous phase (wet atmospheric air) is governed by mass, momentum, energy and species principles, while the dispersed phase (water droplets released from cooling tower) is governed by force, energy and mass balances, from the Lagragian point of view. Both phases are coupled through appropriate source terms in the conservation equations.

\section{Wet air flow governing equations}

The continuous phase is modelled by means of the simplified RANS steady equations:

$$
\begin{aligned}
& \frac{\partial\left(\rho U_{j}\right)}{\partial x_{j}}=0 \\
& \frac{\partial\left(\rho U_{i} U_{j}\right)}{\partial x_{j}}=\frac{\partial}{\partial x_{j}}\left[\mu\left(\frac{\partial U_{i}}{\partial x_{j}}+\frac{\partial U_{j}}{\partial x_{i}}\right)-\frac{2}{3} \mu\left(\frac{\partial U_{j}}{\partial x_{j}}\right) \delta_{i j}-\rho \overline{u_{l} u_{J}}\right]-\frac{\partial p}{\partial x_{i}}+\rho g_{i}, \\
& \frac{\partial\left(\rho c_{p} T U_{j}\right)}{\partial x_{j}}=\frac{\partial}{\partial x_{j}}\left[\kappa \frac{\partial T}{\partial x_{j}}-\rho c_{p} \overline{T^{\prime} u_{J}}\right]
\end{aligned}
$$


where $U$ and $T$ are the averaged velocity and averaged temperature, respectively, and $p$ the relative pressure, difference between the pressure and the ambient pressure. The turbulent stress $-\overline{u_{\imath} u_{\jmath}}$ and the turbulent heat flux $-\overline{T^{\prime} u_{\jmath}}$ are provided from the turbulence closure model, assuming that

$$
-\overline{u_{\imath} u_{\jmath}}=2 v_{t} S_{i j}-\frac{2}{3} k \delta_{i j}, \quad \text { and }-\overline{T^{\prime} u_{\jmath}}=\frac{v_{t}}{P r_{t}} \frac{\partial T}{\partial x_{j}}{ }^{\prime}
$$

being $v_{t}$ and $P r_{t}$ the turbulent kinematic viscosity and turbulent Prandtl number, respectively; $S_{i j}$ is the mean strain tensor, $S_{i j}=\left[\left(\partial U_{i} / \partial x_{j}\right)+\left(\partial U_{j} / \partial x_{i}\right)\right] / 2, \delta_{i j}$ the Krönecker delta and $k$

the kinetic turbulent energy, given by $k=\sum_{j=1}^{j=3} \overline{u_{j}^{2}} / 2$. The well-know $k-\varepsilon$ turbulence model is employed to solve the closure problem. So, two additional equations, the transport of kinetic turbulent energy $(k)$ and the transport of its dissipation rate $(\varepsilon \approx d k / d t)$, are included in the modelling. The standard relationship $v_{t}=C_{\mu}\left(k^{2} / \varepsilon\right)$ is employed, being $C_{\mu}$ an experimental dimensionless constant, equal to 0.09 .

The species equation (Fick's law) is employed in order to model the humidity of the atmospheric air,

$$
\rho U_{i} \frac{\partial \dot{m}_{i^{\prime}}}{\partial x_{i}}=-\frac{\partial J_{i^{\prime}, i}}{\partial x_{i}}
$$

where $J_{i^{\prime} i}$ is the diffusive flux of the $i^{\prime}$ specie:

$$
J_{i^{\prime}, i}=-\rho D_{v, f} \frac{\partial \dot{m}_{i^{\prime}}}{\partial x_{i}}
$$

\section{Water droplets governing equations}

Water droplets are considered as discrete phase. Many droplets are released from the cooling tower. The trajectory $r_{p}$ of a droplet is calculated by means of the integration of the force balance on the particle:

$$
\begin{aligned}
& \frac{d r_{p}}{d t}=U_{p} \\
& \frac{d U_{p}}{d t}=F_{D}\left(U-U_{p}\right)+\frac{g_{r}\left(\rho_{p}-\rho\right)}{\rho_{p}}+\frac{\rho}{\rho_{p}} U_{p} \frac{\partial U}{\partial r_{p}} \\
& F_{D}=\frac{18 \mu}{\rho_{p} D_{p}^{2}} \frac{C_{D} R e_{p}}{24} \\
& C_{D}=a_{1}+\frac{a_{2}}{R e_{p}}+\frac{a_{3}}{R e_{p}^{2}}
\end{aligned}
$$

with $R e_{p}=\left(\rho D_{p}\left|U-U_{p}\right|\right) / \mu$ the Reynolds number of the particle. The coefficients $a_{1}, a_{2}$ and $a_{3}$ are constants used for smooth particles over several ranges of $\operatorname{Re}$ (Morsi et al. [12]); $F_{D}\left(U-U_{p}\right)$ is the drag force per unit particle mass, $g_{r}\left(\rho_{p}-\rho\right) / \rho_{p}$ is the gravity force per unit particle mass, $\left(\rho / \rho_{p}\right) U_{p}\left(\partial U / \partial r_{p}\right)$ is the force due to the pressure gradient in the fluid. The mass exchange of heat and water between the droplets and the wet air is taken into account, doing an energy balance on each droplet, 


$$
m_{p} c_{p} \frac{d T_{p}}{d t}=h A_{p}\left(T-T_{p}\right)+\frac{d m_{p}}{d t} h_{f}
$$

with $d m_{p} / d t$ the evaporation rate on the particle ( $m_{p}$ is the particle mass), $h$ the convective heat transfer and $h_{f}$ the latent heat of water.

The dispersion of particles due to turbulence in the continuous phase is simulated using a stochastic tracking model. In the RANS steady equations the velocity of the fluid is composed by a mean velocity $U_{j}$ and a random velocity fluctuation $u_{j}$. When the trajectory of a droplet is integrated, Eq. (8), $u_{j}$ is kept constant for a certain interval of time $t_{e}$, which depends on the characteristic time scale or lifetime of eddies. The lifetime of the eddies is expressed as $t_{e}=$ $-t_{l} \log (r)$, where $t_{l}$ is the time scale of the Lagrangian flow, $t_{l}=C_{l} \frac{k}{\varepsilon}$; in the turbulence model $k-\varepsilon$, the standard value of $C_{l}$ is 0.15 . The term $r$ is a random number between 0 and 1 . The dispersion is simulated computing each trajectory for a sufficient number of particles (tries).

\section{Interaction between dispersed and continuous phase}

The effects of the water droplets on the atmospheric air is taken into account by means of the incorporation of source terms into the right terms of the equations of the wet air (Eqs. (1-3) and Eq. (5)). $S_{i^{\prime}}$ is the source term of the $i^{\prime}$ specie, and it is incorporated into the mass balance (Eq. (1)) and into the species balance (Eq. (5)). $F_{i}$ is the momentum communicated from the droplets to the air; this source term is added into the balance of kinetic momentum of the wet air (Eq. (2)). $S_{h}$ is the energy source, and it is included in the right term of the energy balance of the continuous phase (Eq. (3)).

\subsection{Solver settings and boundary conditions}

The results presented in this work are obtained numerically by using the general-purpose AnsysFluent code (V. 14). The "SIMPLE" algorithm is employed to solve the coupling between continuity and momentum equations. An "upwind" second-order differencing scheme is applied for the convective terms of the equations. Regarding the numerical convergence, the normalized residuals for mass and momentum variables had to be below $10^{-5}$, while energy, species and turbulent variables had to be below $10^{-7}$.

The profiles for velocity, turbulence kinetic energy and dissipation rate are taken from the work of Richards and Hoxey [13] for the Atmospheric Boundary Layer $(A B L)$ are used in the numerical modelling:

$$
\begin{aligned}
& U(z)=\frac{u_{A B L}^{*}}{k_{v}} \ln \left(\frac{z+z_{0}}{z_{0}}\right), \\
& k=\frac{u_{A B L}^{* 2}}{\sqrt{C_{\mu}}}, \\
& \varepsilon(z)=\frac{u_{A B L}^{* 3}}{k_{v}\left(z+z_{0}\right)^{\prime}}
\end{aligned}
$$

being $u_{A B L}^{*}$ is the friction velocity, $k_{v}$ is the von Kárman constant (taken as 0.41 ) and $z_{0}$ the aerodynamic roughness height of the terrain. By means of the mean experimental velocity 
taken from the meteorological tower at $z=25 \mathrm{~m}$ and $z=40 \mathrm{~m}$, it is possible to find the values of the constants $u_{A B L}^{*}$ and $z_{0}$ for each case.

The temperature profile is found as linear:

$$
T(z)=\beta+\alpha \cdot z
$$

where the constants $\alpha$ and $\beta$ are obtained from the experimental mean temperatures at $z=$ $25 \mathrm{~m}$ and $z=40 \mathrm{~m}$ taken by the meteorological tower. The values of $\beta$ vary from $10.8{ }^{\circ} \mathrm{C}$ (winter days) to $29.9{ }^{\circ} \mathrm{C}$ (summer days). The coefficient $\alpha$ has relation with the atmospheric stability (vertical temperature gradient) and it takes values that vary from $-0.004 \mathrm{~K} / \mathrm{m}$ to $-0.023 \mathrm{~K} / \mathrm{m}$.

The specific humidity at the inlet boundary is defined as a constant, with the value taken from the meteorological station. Symmetry boundary condition was selected for the domain sides. The top surface is a non-slip wall with the velocity of Eq. (12) at $z=400 \mathrm{~m}$, and the temperature of Eq. (15) at $z=400 \mathrm{~m}$. In this way, the horizontal homogeneity of the thermal $A B L$ and the viscous $A B L$ is achieved. Outflow boundary condition is used for the domain outlet, which assumes a fully developed flow at the outlet. There are two ground surfaces (see Fig. 2): the interior circle (where the buildings are) and the ground exterior to the circle. Both grounds are treated as non-slip wall with the temperature corresponds to Eq. (15) at $z=0 \mathrm{~m}$. The internal ground has null roughness length, because the buildings incorporate the roughness effects of the ground. The external ground has the roughness length $z_{0}$ taken from Eq. (12). Theoretically, the roughness length is approximately one-tenth of the height of the surface roughness elements. In our cases the roughness length varies from $0.02 \mathrm{~cm}$ to $2.4 \mathrm{~m}$. This variation is related to the wind direction of the day; if the air comes from the part where there are open flat terrains, the roughness is very low, whereas when it comes from the area where there are buildings, the parameter $z_{0}$ is higher.

Conditions at the cooling tower exit (air velocity, temperature and humidity) are set to constant values. Water mass flow was distributed uniformly on the surface. Droplet size distribution injection at cooling tower exit of the model is defined through the Rosin-Rammler's equation, based on the assumption that an exponential relationship exists between droplet diameter $D_{p}$, and mass fraction of $M_{D_{p}}$ of droplets with a diameter higher than $D_{p}$,

$$
M_{D_{p}}=e^{-\left[D_{p} / \overline{D_{p}}\right]^{n}}
$$

where $\overline{D_{p}}$ is the average droplet diameter and $n$ is a fit coefficient. The values of the air arising of the cooling tower (velocity, temperature and humidity), the water flow mass and the values of the constants $\overline{D_{p}}$ and $n$ are taken from the emission test of the case.

\subsection{Meshing}

As explained before, the domain is an $800 \times 800 \times 400 \mathrm{~m}$ hexahedron, and the buildings are in the middle of the domain. The geometry has been divided in internal solids around the buildings, in order to get a high quality mesh (hexahedral with low skewness elements). The generated mesh is a structured hexahedral grid, with different sizes of cells, using thick elements in the farther 
areas from the buildings, and thinner one in the nearby of them, where more resolution is needed (see Fig. 3). The employed mesh has 3,072,411 cells. A detailed study of the influence of the grid size on the obtained results was carried out by authors Consuegro et al. [7]. In that work, several meshes, ranging from 643,443 to 726,468 cells (no surrounding buildings), and from 313,561 to $2,978,575$ cells (surrounding buildings included) were employed. The independence of the results was obtained with meshes from 662,262 to $1,762,182$ cells. However, in this work (and also in that previous work), meshes with at least $2.5 \cdot 10^{6}$ cells are used in most cases, in order to obtain accurate numerical results.

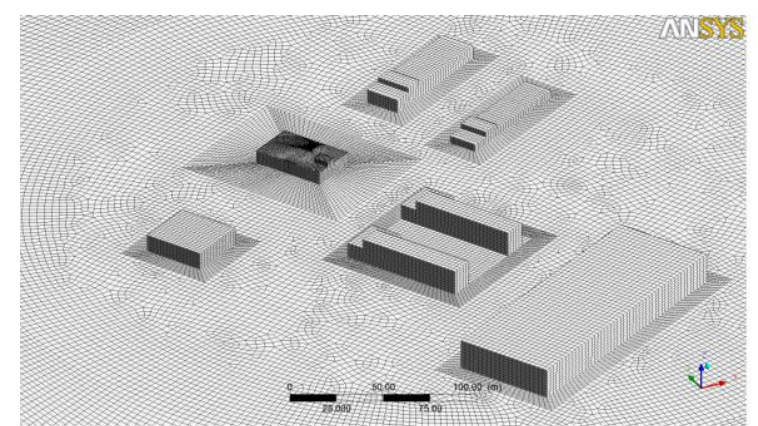

a)

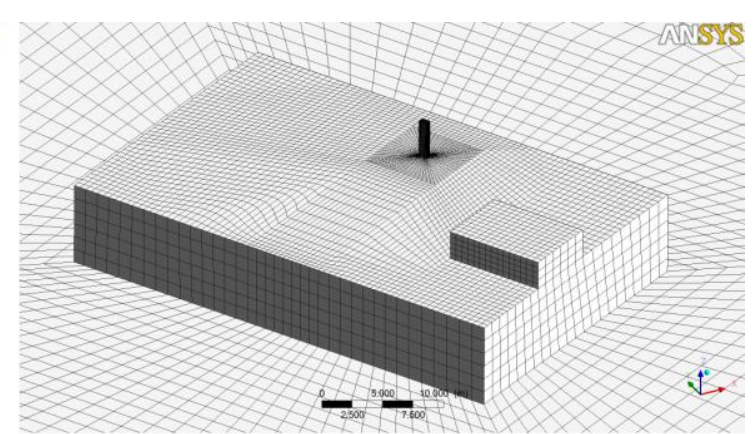

b)

Figure 3. a) Mesh around the buildings. b) Mesh in the area of the mechanical cooling tower.

\subsection{Uncertainty estimation}

A numerical uncertainty estimation based on the Grid Convergence Index (GCI [14]) was carried out. Three different sets of grid resolutions were selected with refinement factors higher than 1.3. Three different representative sizes of cells are outlined $\left(\delta_{1}\right.$ (fine) $<\delta_{2}$ (medium) $<$ $\left.\delta_{3}(\operatorname{coarse})\right)$, for each $\mathrm{GCl}$ test. Thus $r_{21}=\delta_{2} / \delta_{1}, r_{32}=\delta_{3} / \delta_{2}$, and the apparent order of the method can be obtained from

$$
N=\frac{1}{\ln \left(r_{21}\right)}\left[\ln \left|\frac{\varepsilon_{32}}{\varepsilon_{21}}\right|+\ln \left(\frac{r_{21}^{N}-1 \times \operatorname{sign}\left(\varepsilon_{32} / \varepsilon_{21}\right)}{r_{32}^{N}-1 \times \operatorname{sign}\left(\varepsilon_{32} / \varepsilon_{21}\right)}\right)\right]
$$

with $\varepsilon_{i j}=\varphi_{i}-\varphi_{j}$, being $\varphi_{i}$ the value of a key variable (drift deposition in our case), calculated for the grid $j$. Steps 4 and 5 [13] provide

$$
G C I_{\text {fine }}=\frac{\left(F_{S}\right) e_{a}^{21}}{r_{21}^{N}-1}, \quad G C I_{\text {coarse }}=\frac{\left(F_{S}\right) e_{a}^{32}}{r_{32}^{N}-1}
$$

where $F_{S}$ is a safety coefficient and $e_{a}^{i j}$ is the extrapolated relative error of the key variable $\left(e_{a}^{i j}=\right.$ $\left.\frac{\left|\varphi_{i}-\varphi_{j}\right|}{\varphi_{j}}\right)$. Using sets of three grid studies and $F_{S}=1.25$, the method results in a $\mathrm{GCl}$ with a $95 \%$ confidence interval. The $\mathrm{GCl}$ value obtained with $N=1$ is an indicator of the sensibility of the error band to the observed value of $N$. Different meshes are considered for the $\mathrm{GCl}$ estimation: A $(994,520), A 1$ (as A, but finer at the deposition area), B (1,762,182 cells), C (2,978,575 cells), D $(3,072,411$ cells), and D1 (as D, but finer at the deposition area). The obtained results are shown is Table 2. Note that the maximum value of $\mathrm{GCl}_{\text {fine }}$ is $4.5 \%$, imposing that $\mathrm{N}=1$ in all cases.

\begin{tabular}{|c|c|c|c|c|}
\hline Set of meshes & $\mathrm{A}-\mathrm{B}-\mathrm{C}$ & $\mathrm{A} 1-\mathrm{B}-\mathrm{C}$ & $\mathrm{A}-\mathrm{B}-\mathrm{D}$ & $\mathrm{A}-\mathrm{B}-\mathrm{D} 1$ \\
\hline $\mathrm{GCl}_{\text {fine }}$ & $4.5 \%$ & $3.5 \%$ & $4.1 \%$ & $1.9 \%$ \\
\hline
\end{tabular}

Table 2. $\mathrm{GCl}$ results (with $\mathrm{N}=1$ ), for drift deposition simulations. Meshes A-A1-B-C-D-D1 from 994,520 to 3,072,411 cells. 


\subsection{Experimental results}

The experimental results of total water deposition on the floor are used to validate the numerical modelling. The experimental procedure gives the deposition on the 20 sensitive papers; now then, the total deposition on the floor must be calculated by means of the integration of the deposition in each point of the floor. Two mathematical methods are considering for solving that problem: statistical regression and interpolation. Both methods use the data measured in the 20 sensitive papers for predicting the corresponding data at any point on the floor.

Classical statistical regression such as minimum squares could be proposed for obtaining a continuous function of the deposition on the floor. However, this method is not suitable for the proposed problem, because it needs a high number of experimental data in order to ensure a good fitting; in addition, it is remarkable that the very abrupt nature of the experimental data makes that one paper could have 100 times more deposition than other. However, a numeric interpolation method could solve the problem, because the interpolation function is bounded to pass through the data points. There are several methods of interpolation. The piecewise interpolation could provide poor results when the grid formed by the sensitive papers is irregular, and if the distribution of the data was very abrupt, the piecewise function was not smooth enough. A useful alternative could be the biharmonic interpolation; in fact, this technique gives smooth functions even with irregular grids. The biharmonic interpolation is more flexible than the piecewise interpolation; in fact, it is possible to extrapolate with it. Figure 4 shows the comparison of three interpolation methods (piecewise linear, piecewise cubic and biharmonic) and a statistical regression. The blue points correspond to the experimental data taken from the sensitive papers. It can be concluded that the biharmonic interpolation is the most suitable for this work due to its precision, simplicity and flexibility.

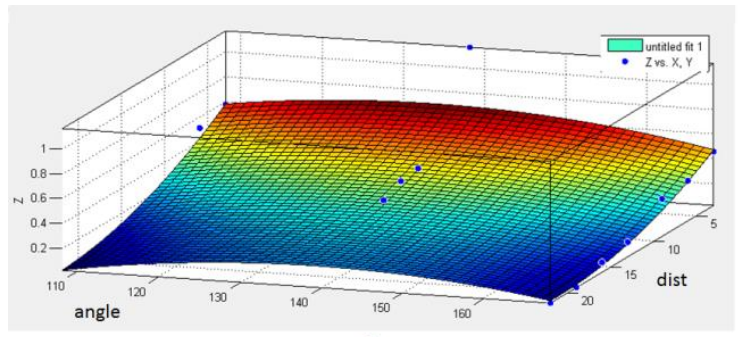

a)

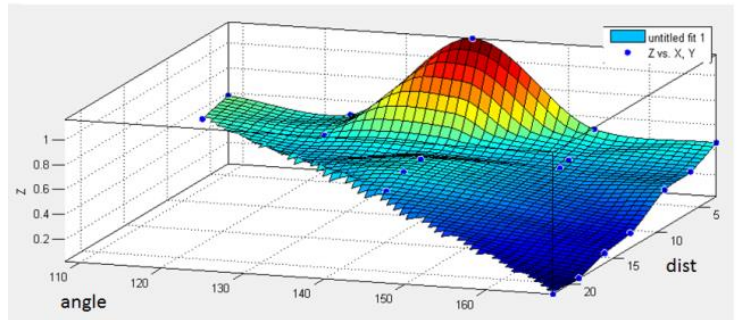

c)

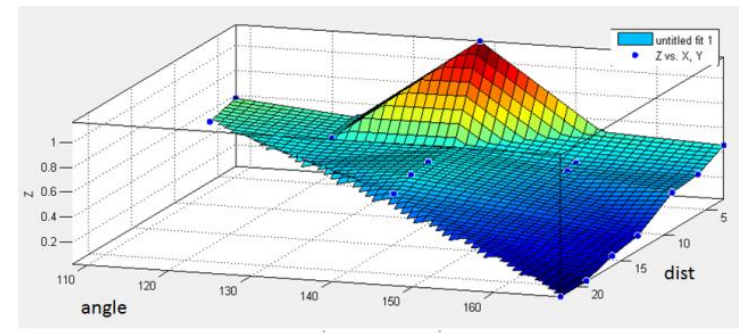

b)

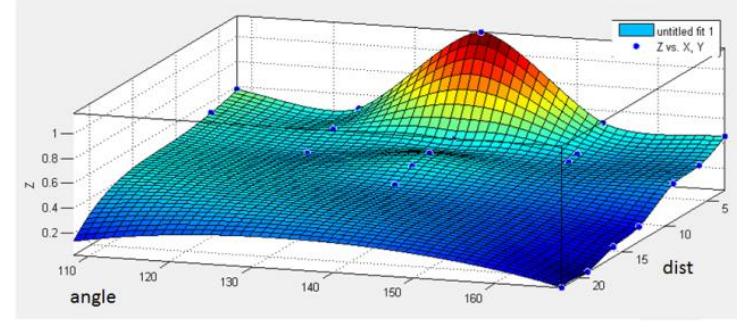

d)

Figure 4. Comparison of different methods for correlating the experimental data of the deposition of droplets. 
Since the biharmonic interpolation seems to be the best option, it deserves a more detailed explanation. The biharmonic spline interpolation finds the function $u_{b h}$ that passes through the data points, satisfying the biharmonic equation. In this work, a cylindrical coordinate system is employed, with the origin in the cooling tower. So the problem to solve is:

$$
\begin{aligned}
& \Delta\left[\Delta u_{b h}\left(\rho_{c}, \theta_{c}\right)\right]=0, \\
& u_{b h}\left(\rho_{c i}, \theta_{c i}\right)=d_{i}, \quad \text { for } i=1, \ldots, 20,
\end{aligned}
$$

where $\rho_{c i}, \theta_{c i}$ and $d_{i}$ are the vectors that include the location and the experimental deposition of each sensitive paper( see Sandwell [15], for instance).

Physically, the studied problem is similar to forcing an elastic sheet for matching the data points. Satisfying the biharmonic equation, the minimum curvature is ensured (Briggs [16]). This minimum curvature method is suitable when the data presents peaks, as occurs in our case. Deng and Tang [17] described the advantages of the method, and they also presented an algorithm to accelerate the method.

\subsubsection{Experimental total deposition}

For each experimental case, the interpolating function is integrated for obtaining the total deposition of the case. The biharmonic interpolation can extrapolate and estimate the deposition of the points located out of the area enclosed by the sensitive paper. However, the extrapolation could give misleading deposition; it is hazardous to estimate the deposition outside of the domain from the data inside the domain. Hence, in this work, the integration of the interpolating function is done only over the domain enclosed by the sensitive papers (see Fig. 5). Instead of doing directly an analytical integration of the biharmonic function over the domain, it is taken advantage of the mesh generated in the numerical modelling for doing a numerical integration, evaluating the interpolating function in each cell and summing them for obtaining the total experimental deposition:

$$
\operatorname{dep}_{\text {tot }}=\sum_{j} A_{j} \cdot d_{j}
$$

where $A_{j}$ is the area of the cell $j$, and $d_{j}$ is the value of the interpolating function in the cell. Note the sum only include the cells situated inside the domain of integration. 


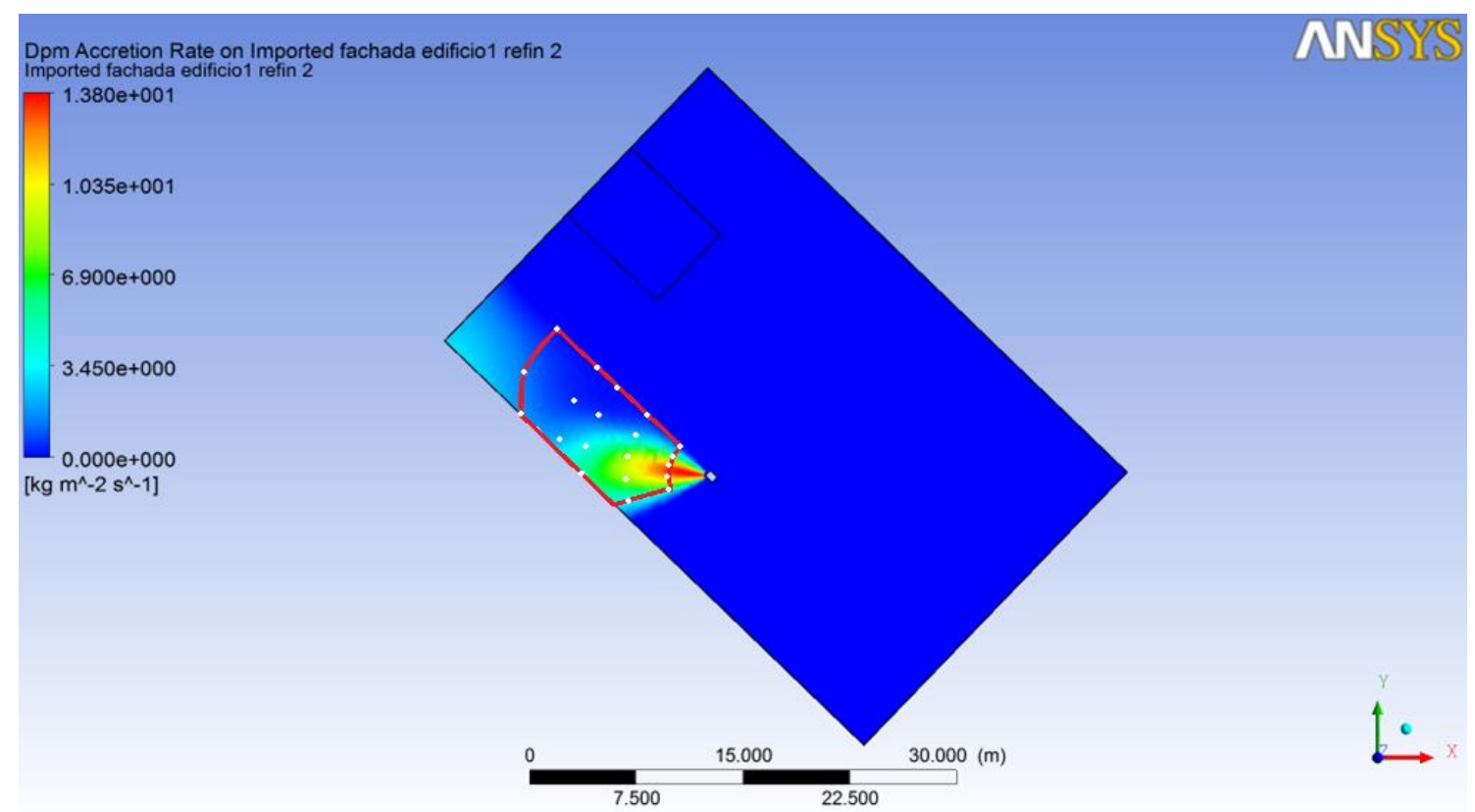

Figure 5. Experimental deposition obtained by means of the biharmonic interpolation. White points correspond to the location of the sensitive papers (known data). The red line is the integration limit, formed by the peripheral sensitive papers.

\subsection{Validation of the numerical modelling}

In paper [7], an experimental validation of the numerical modelling is done, comparing the deposition in each paper, the wind velocity and the diameter of the deposited droplets on each paper. In this paper, the experimental validation is done by means of the comparison of the total deposition of water on the area of the floor bounded by the water sensitive paper (see Fig. 5) obtained numerically and experimentally. A total of 14 experimental cases have been done. For each experimental case, a numerical simulation has been carried out, using the atmospheric and droplets conditions of the correspondent experimental case (see Table 3).

\begin{tabular}{|c|c|c|c|c|c|}
\hline No. & $\begin{array}{c}\text { Air } \\
\text { temperature } \\
(\mathrm{o} C)\end{array}$ & $\begin{array}{c}\text { Air relative } \\
\text { humidity } \\
(\%)\end{array}$ & $\begin{array}{c}\text { Wind } \\
\text { velocity } \\
(\mathrm{m} / \mathrm{s})\end{array}$ & $\begin{array}{c}\text { Wind } \\
\text { direction }\end{array}$ & $\begin{array}{c}\text { Droplet } \\
\text { mean } \\
\text { diameter } \\
\left(\times 10^{-3} \mathrm{~m}\right)\end{array}$ \\
\hline 1 & 23.85 & 65.96 & 3.09 & $\mathrm{~W}$ & 0.072 \\
\hline 2 & 17.45 & 38.45 & 2.95 & $\mathrm{SE}$ & 0.330 \\
\hline 3 & 10.70 & 66.65 & 5.89 & $\mathrm{SE}$ & 0.332 \\
\hline 4 & 15.65 & 41.89 & 2.64 & $\mathrm{SE}$ & 0.033 \\
\hline 5 & 13.85 & 41.89 & 2.77 & $\mathrm{SE}$ & 0.033 \\
\hline 6 & 9.16 & 34.09 & 3.26 & $\mathrm{SE}$ & 0.332 \\
\hline 7 & 17.75 & 58.49 & 2.04 & $\mathrm{NW}$ & 0.331 \\
\hline 8 & 17.45 & 58.49 & 2.46 & $\mathrm{NW}$ & 0.331 \\
\hline 9 & 21.43 & 59.09 & 3.46 & $\mathrm{NW}-\mathrm{W}$ & 0.281 \\
\hline 10 & 20.20 & 59.09 & 2.70 & $\mathrm{NW}-\mathrm{W}$ & 0.281 \\
\hline 11 & 28.81 & 24.20 & 2.39 & $\mathrm{NW}$ & 0.327 \\
\hline 12 & 27.15 & 24.20 & 2.32 & $\mathrm{NW}$ & 0.327 \\
\hline 13 & 23.55 & 49.77 & 2.85 & $\mathrm{SE}$ & 0.357 \\
\hline
\end{tabular}


Figure 6 shows the comparison between the numerical and the experimental total deposition for the Case 13, which is described in Table 3. It is observed that the numeric deposition (Fig.6a) is more concentrated than the experimental one (Fig.6b). The numerical deposition takes less area but with higher punctual deposition than the experimental. This phenomenon can be explained by the fact that the numerical modelling is steady, with the wind blowing in only one direction, while the experimental deposition is taken for a given period of time ( $30 \mathrm{~min})$. For that time the wind is not always blowing in one direction. In spite of this difference in the area taken by the deposition, the total numerical and experimental depositions on the floor are very similar $\left(2.85 \times 10^{-5} \mathrm{~kg} / \mathrm{s}\right.$ and $2.81 \times 10^{-5} \mathrm{~kg} / \mathrm{s}$, respectively). In the paper [7], this disagreement between the dispersion of numerical and experimental deposition is solved by means of "segmented simulation", three steady simulations were carried out for each experimental case. Each simulation had a different wind direction; the numerical deposition on each point of the floor was the weighted average of the deposition calculated in each simulation. However, the aim of this work is to estimate the total amount of water deposited on the floor; it is not necessary to know the exact deposition in each point of the floor. A "segmented simulation" would increase the computational time and it hardly would change the total amount of deposition.

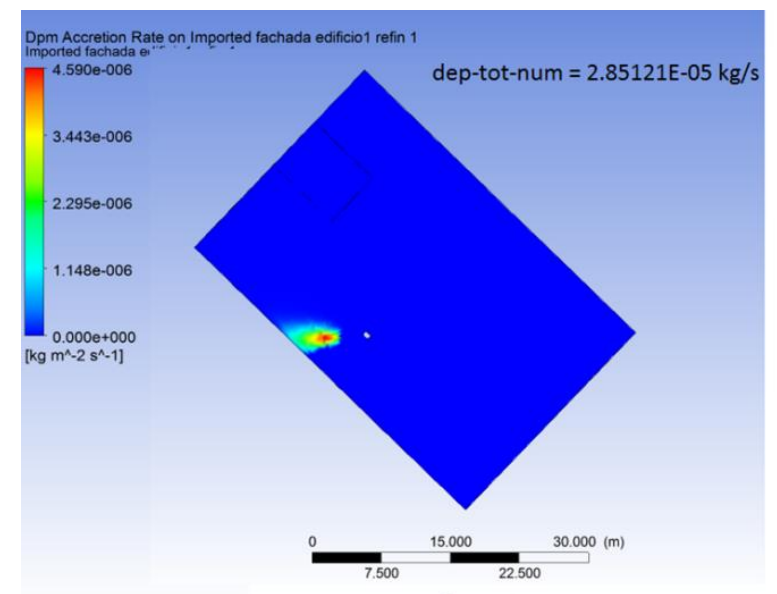

a)

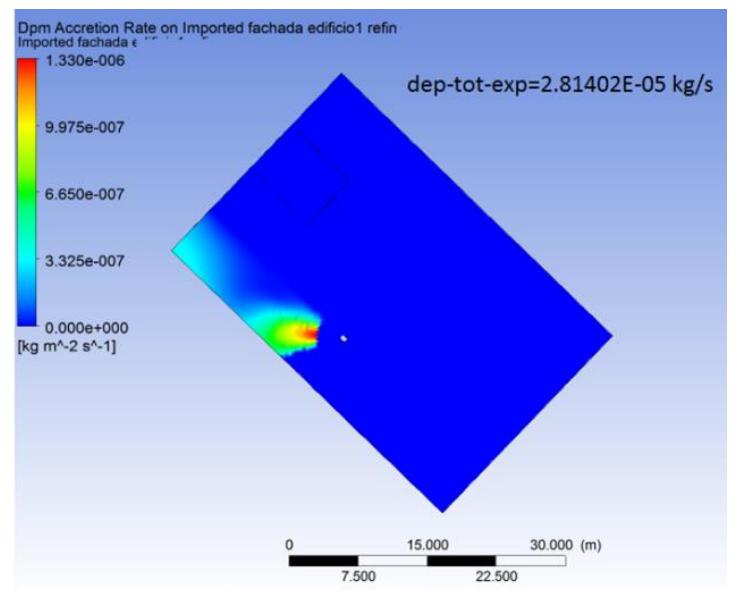

b)

Figure 6. Comparison of numerical (a) and experimental deposition (b) in the Case 13 (Table 1).

The experimental cases were classified into three categories based on the wind fluctuations during the deposition test. Cases with wind direction perturbation are those cases where more of the $2 \%$ of the experimental points taken in the emission test have wind directions outside of the limit directions of the domain enclosed by the sensitive papers (see Fig. 5). Cases with wind velocity perturbation correspond to those cases where more of the $5 \%$ of the experimental data points taken in the emission test have wind velocities lower than $2 \mathrm{~m} / \mathrm{s}$. The experimental cases in which there is neither wind direction perturbation nor wind velocity perturbation are considered as cases without perturbation. The dimensionless mass flow deposition on the floor $\phi$ is employed as reference parameter to compare experimental and numerical deposition on the floor. It is defined as the fraction of water released from the cooling tower that drops on the area limited by the sensitive papers. This is done by means of the division of the deposition of 
water on the floor $(\mathrm{kg} / \mathrm{s})$ into the mass flow rate of water $(\mathrm{kg} / \mathrm{s})$ that escaped through the cooling tower. Figure 7 corresponds to the aforementioned validation. Each point corresponds to a case (there are 14 points), $X$-coordinate of a case is its numerical deposition, while $Y$ coordinate is its experimental deposition. The diagonal line represents the locus of experimental deposition equal to numerical one. The distance between each point and the line quantify the level of coincident between the experimental and the numerical deposition.

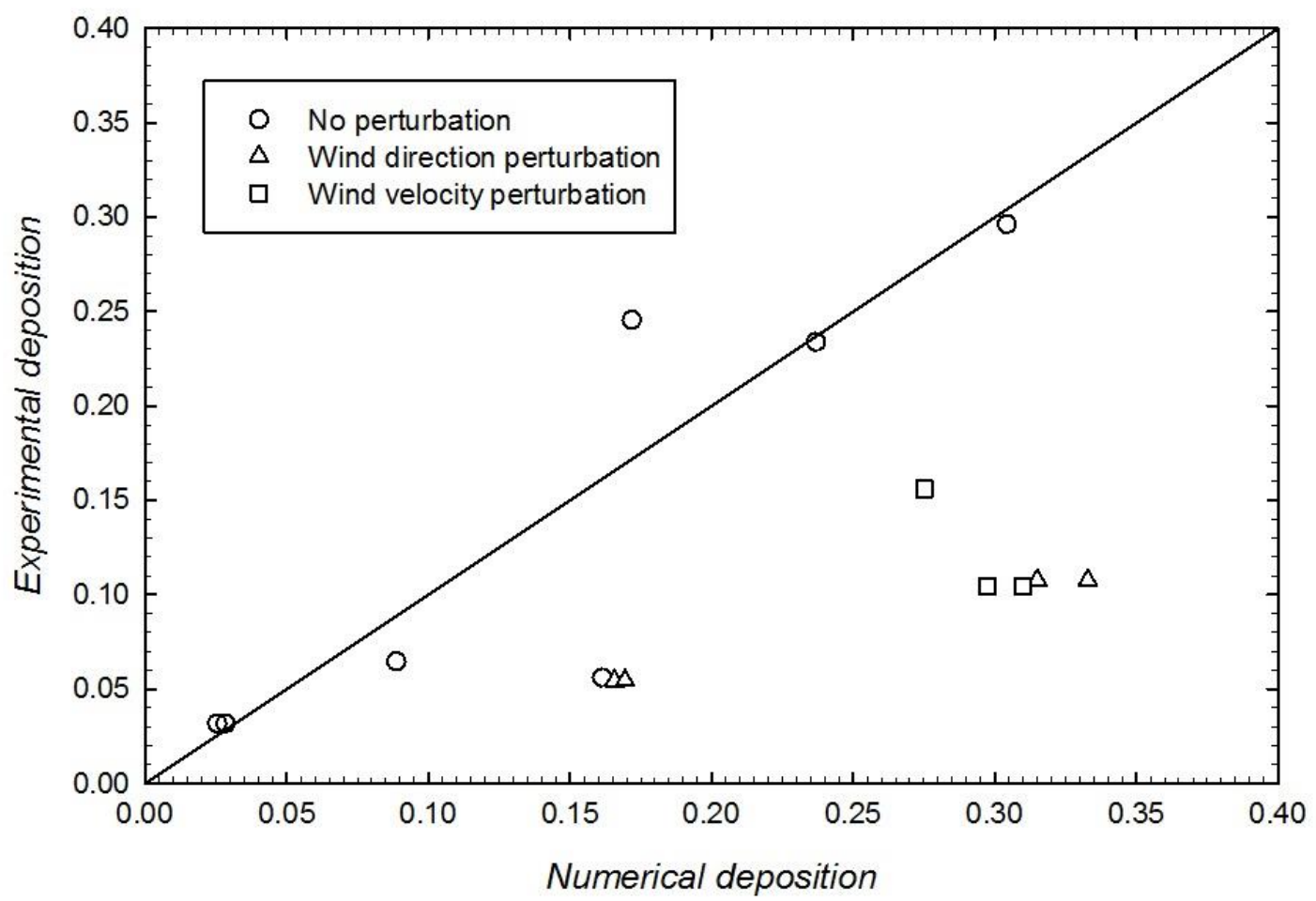

Figure 7. Comparison between the numerical and the experimental results obtained for deposition.

Note in Fig. 7 that some results of the experimental deposition are significantly less than those corresponding to the numerical simulation. This is due to the two main sources of perturbation mentioned above: the fluctuation of the wind direction and the fluctuation of the wind velocity. As explained above, our numerical modeling is steady; because of this, all the deposition is concentrated on little space. However, during the experimental deposition test, the wind direction has fluctuations that can produce deposition on the further lines from the mean direction of the wind. In some cases, these fluctuations can produce deposition outside of the domain limited by the sensitive papers, generating less experimental deposition (triangles in Fig. 7 , wind direction perturbation). The other main source of perturbation is due to the wind velocity fluctuations. In all the cases, the closest papers are $3 \mathrm{~m}$ from the cooling tower. But in some experimental cases, because of the unpredictable wind velocity fluctuation, part of the water was deposited closer than $3 \mathrm{~m}$, and that water is not included in the integral. Against that, in the numerical simulation, where the deposition is more concentrated, the integral covers all the deposition. For this reason, in some cases the numerical deposition is higher than the experimental deposition (squares in Fig. 7, wind velocity perturbation). Figure 8 corresponds to Case 9. Note that the main part of the numerical deposition is inside the integration domain, while in the experimental case, some deposition seems to be out of the domain (near the tower). 
Here, the numeric deposition is $3.93 \times 10^{-5} \mathrm{~kg} / \mathrm{s}$, while the experimental deposition is lower, $1.28 \times 10^{-5} \mathrm{~kg} / \mathrm{s}$.

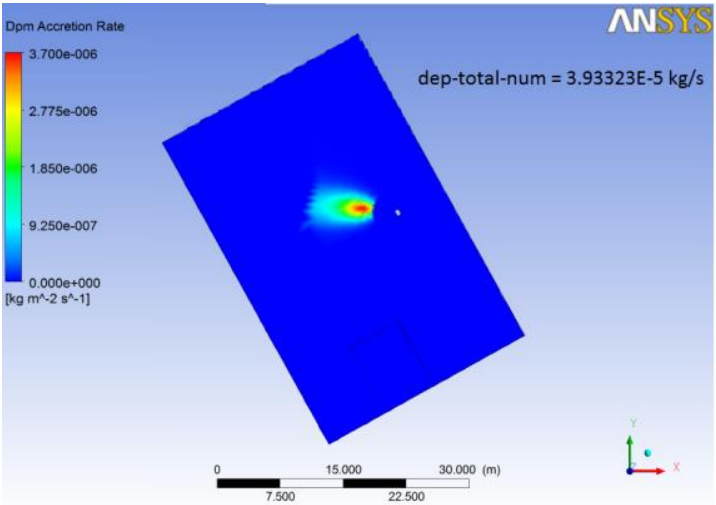

a)

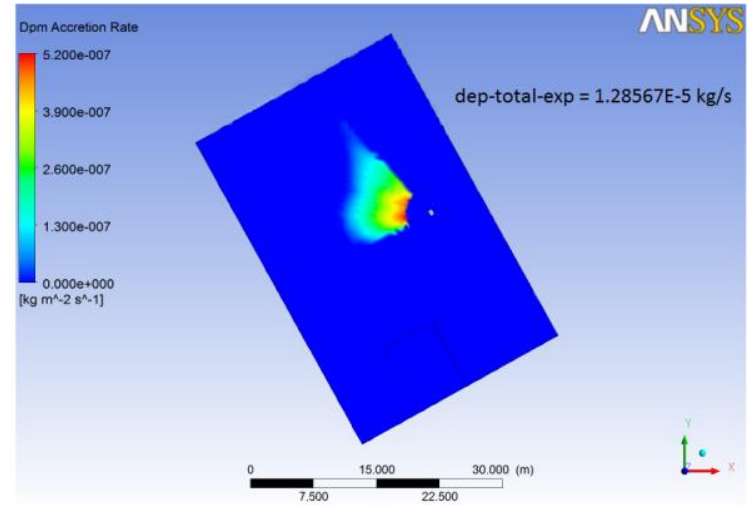

b)

Figure 8. Comparison of numerical (a) and experimental deposition (b) in the Case 9 (Table 1).

The fluctuations in wind direction and velocity produce a more dispersed deposition, generating in some cases deposition out of the domain of integration; however, in the cases without perturbation, although the numerical deposition is more concentrated than the experimental one, the total deposition in both of them are very similar (see Fig. 6). This leads us to conclude that in the cases with perturbations in direction or velocity of the wind, the disagreement between numerical and experimental data is not due to an incorrect simulation. Hence the total numerical deposition is higher than the experimental one because part of this is out of the integration domain. Since this study focuses mainly on the evaporation, which has a strong relation with the total deposition, the 14 cases were used to analyze the droplets evaporation.

\subsection{Description of droplets evaporation}

\section{Evaporation}

The regarded cases of Table 3 have different atmospheric conditions and different size of droplets. Therefore, it can be expected that they had different evaporation behaviours. Depending on the atmospheric and droplets conditions, three main evaporation patterns can be identified. They are described following.

Cases 4 and 5 illustrate the first pattern. In these cases most of the droplets evaporate. In fact, the lifetime of the droplets is so short that less than $10 \%$ of the water reaches the ground; the rest evaporates completely before falls on the ground. Both cases have a common feature; the mean diameter of the droplets is 10 times lower than in the other cases. These results indicate that there is a clear relation between the lifetime and the size of the droplets. Figure 9 shows the droplets in Case 4 , where $92.6 \%$ of the water evaporates, and therefore the total deposition on the floor represents a $7.4 \%$ of the water released from the tower. 


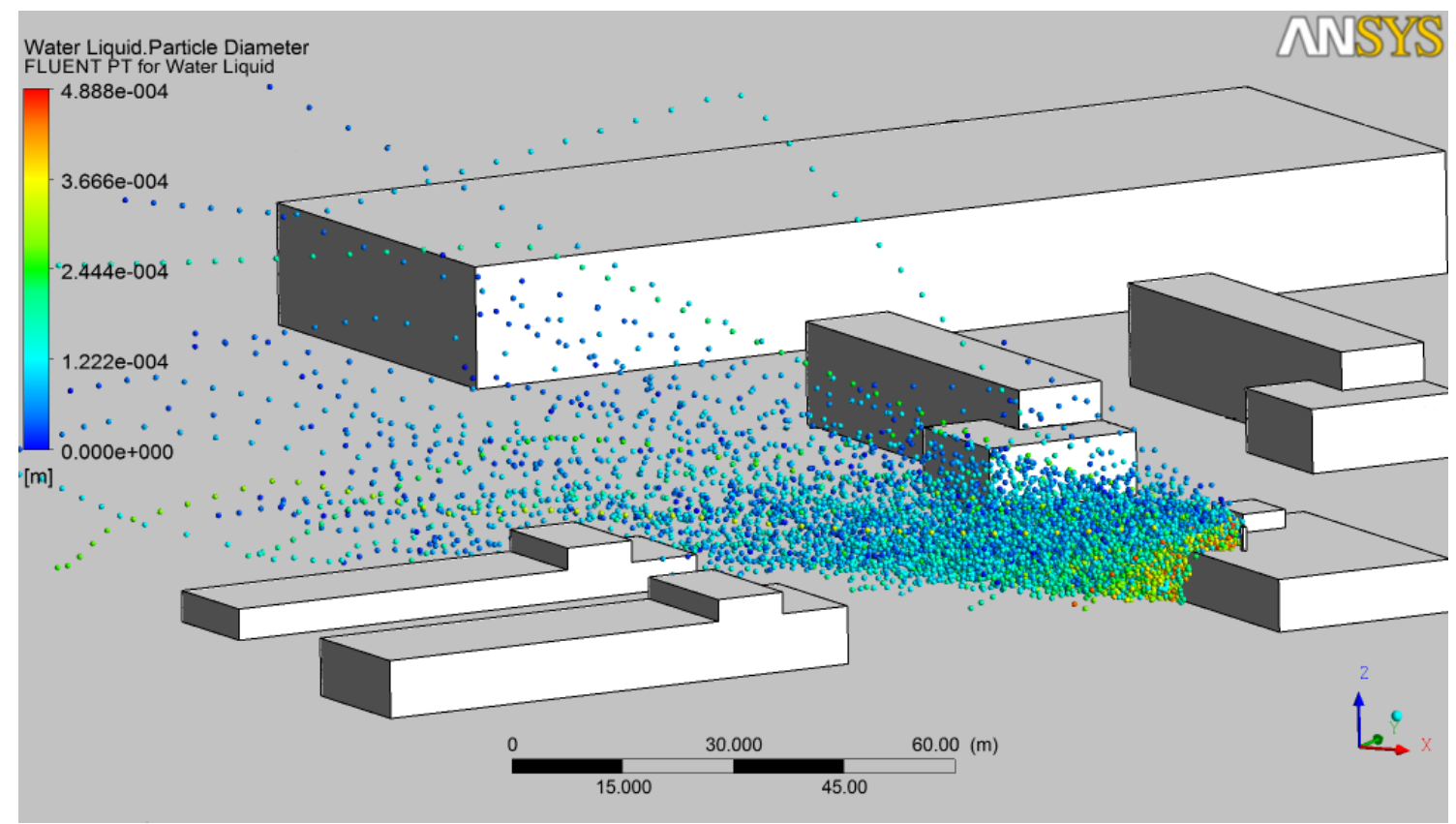

Figure 9. Droplets trajectories in Case 4. The colour show the droplets diameter. Most of the water droplets evaporates completely because of the small size of the released droplets.

Cases 3 and 6 illustrate the second pattern. In those cases, evaporation is much less relevant, compared to the above pattern; in fact, more than $80 \%$ of the water deposites, and the rest scape out the domain. In both cases the droplets scape from the cooling tower with very low temperature (8.74을 $\mathrm{C}$ and $4.31^{\circ} \mathrm{C}$, respectively), and in both cases the air temperatures (11.8 ${ }^{\circ} \mathrm{C}$ and $9.81^{\circ} \mathrm{C}$, respectively) are such that the droplets could not reach the temperature necessary to start the evaporation, which is $T_{\text {vap }}=10.85^{\circ} \mathrm{C}$ in the numerical modelling. In Case 6 , there is not any evaporation. However, in Case 3, $2 \%$ of the water evaporates, which can be explained because the droplets reach the limit temperature $T_{\text {vap }}$. Figure 10 corresponds to Case 6 . The water droplets scape with $4.31^{\circ} \mathrm{C}$, the external air has $9.81^{\circ} \mathrm{C}$, so there is an inert cooling of the droplets, by means of convection between the air and the droplets, but they can not reach the necessary temperature $T_{\text {vap }}$. There is not any evaporation, $82.8 \%$ of the water deposited on the floor and $17.2 \%$ scape out of the domain. 


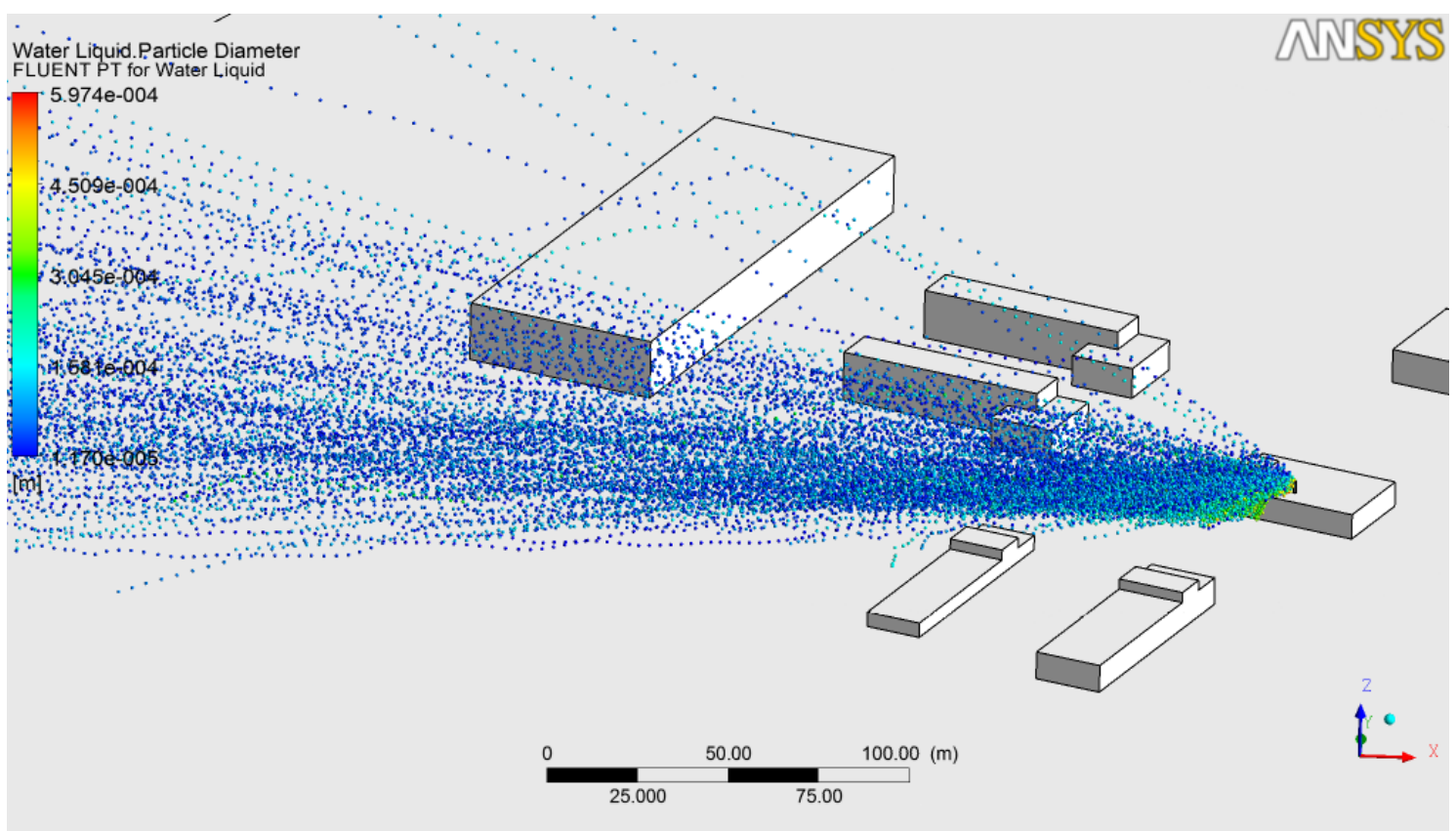

Figure 10. Droplets trajectories in Case 6. There is not any evaporation because the atmospheric temperature is so low that the droplets can not reach the minimal temperature to start the evaporation.

The third pattern occurs when the mean diameter of the droplets is higher than $100 \mu \mathrm{m}$, and the air temperature is not lower than $10.85 \% \mathrm{C}$. In those cases, a range comprised between $40 \%$ and $60 \%$ of the mass of water released from the cooling tower evaporates, and the rest deposited on the floor. Really, this behaviour can be found in most of the cases. Figure 11 shows the droplets on Case 9 , in which a $53.2 \%$ of the water deposited on the ground, whereas a $46.8 \%$ evaporates.

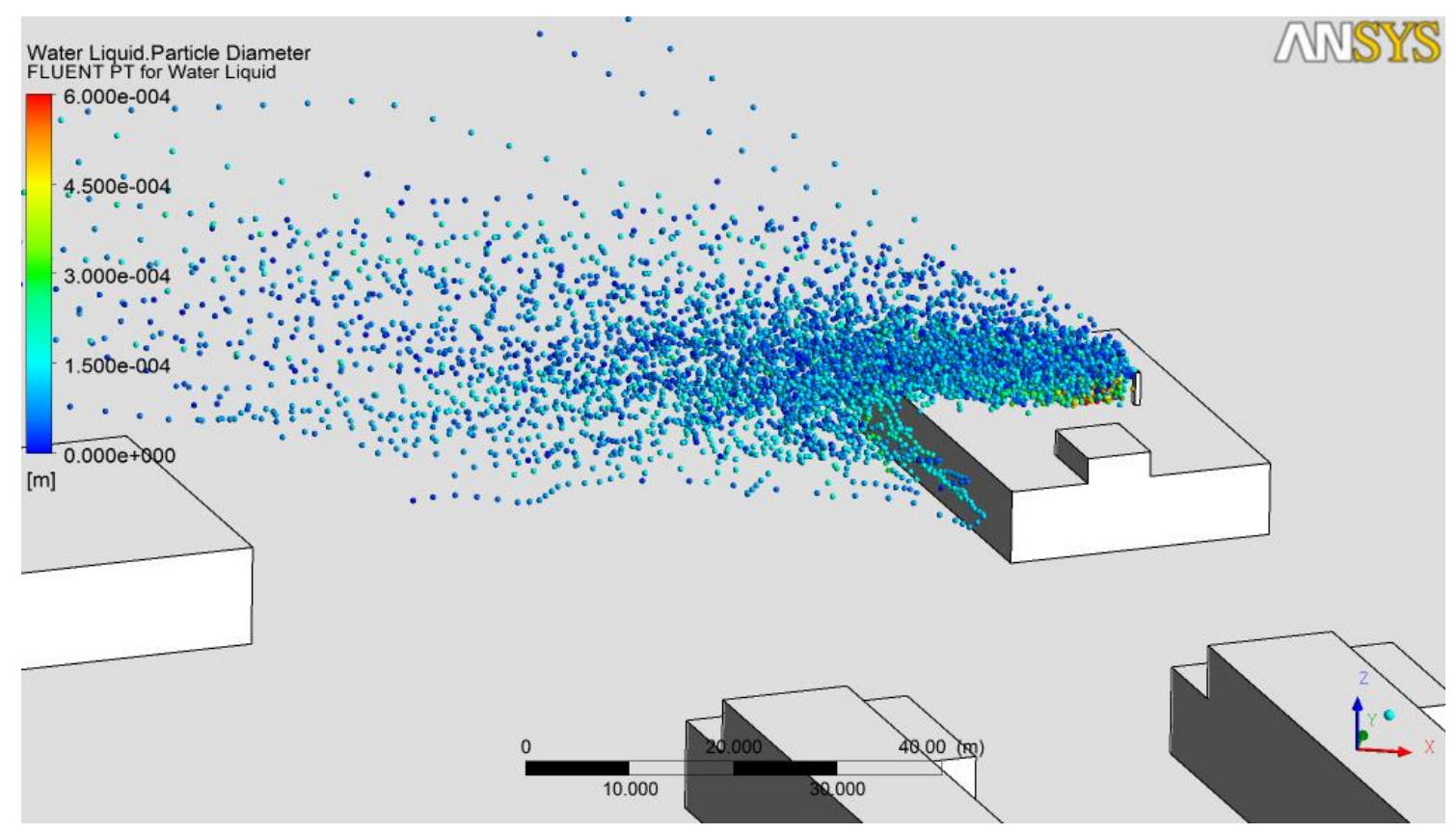

Figure 11. Droplets trajectories in Case 9. When the atmospheric temperature is not so low, and the droplets are not so small, a significant part of the water evaporates, and the rest deposites on the floor.

Table 4 shows the fate of the mass of the water released from the cooling tower in each simulated case. As mentioned above, when the droplets are small, there is more evaporation. Whereas when the air temperature is less than $10.85^{\circ} \mathrm{C}$, there is not any evaporation. This fact 
indicates on the one hand that the lifetime of the particles is concerned with the diameter of the droplet, and on the other hand that there is evaporation only if the temperature of the droplet overcomes the limit temperature $T_{\text {vap }}=10.85^{\circ} \mathrm{C}$.

\begin{tabular}{|c|c|c|c|c|c|c|c|c|}
\hline \multirow{2}{*}{ No. } & \multirow{2}{*}{$\begin{array}{c}\text { Air } \\
\text { temp } \\
(\stackrel{\circ}{ } \text { C) }\end{array}$} & \multirow{2}{*}{$\begin{array}{c}\text { Air } \\
\text { relative } \\
\text { humidity } \\
(\%)\end{array}$} & \multirow{2}{*}{$\begin{array}{c}\text { Wind } \\
\text { Velocity } \\
(\mathrm{m} / \mathrm{s})\end{array}$} & \multirow{2}{*}{$\begin{array}{c}\text { Wind } \\
\text { direction }\end{array}$} & \multirow{2}{*}{$\begin{array}{c}\text { Droplet } \\
\text { mean } \\
\text { diameter } \\
\left(\times 10^{-3} \mathrm{~m}\right)\end{array}$} & \multicolumn{3}{|c|}{ Water fate } \\
\hline & & & & & & deposited & evaporated & escaped \\
\hline 1 & 23.85 & 65.96 & 3.09 & W & 0.072 & $27.2 \%$ & $72.8 \%$ & $0.0 \%$ \\
\hline 2 & 17.45 & 38.45 & 2.95 & SE & 0.330 & $51.7 \%$ & $48.4 \%$ & $0.0 \%$ \\
\hline 3 & 10.70 & 66.65 & 5.89 & SE & 0.332 & $82.7 \%$ & $1.8 \%$ & $15.5 \%$ \\
\hline 4 & 15.65 & 41.89 & 2.64 & SE & 0.033 & $7.4 \%$ & $92.6 \%$ & $0.0 \%$ \\
\hline 5 & 13.85 & 41.89 & 2.77 & SE & 0.033 & $8.8 \%$ & $91.2 \%$ & $0.0 \%$ \\
\hline 6 & 9.16 & 34.09 & 3.26 & SE & 0.332 & $82.8 \%$ & $0.0 \%$ & $17.2 \%$ \\
\hline 7 & 17.75 & 58.49 & 2.04 & NW & 0.331 & $59.5 \%$ & $40.5 \%$ & $0.0 \%$ \\
\hline 8 & 17.45 & 58.49 & 2.46 & NW & 0.331 & $57.8 \%$ & $42.2 \%$ & $0.0 \%$ \\
\hline 9 & 21.43 & 59.09 & 3.46 & NW-W & 0.281 & $53.2 \%$ & $46.8 \%$ & $0.0 \%$ \\
\hline 10 & 20.20 & 59.09 & 2.70 & NW-W & 0.281 & $55.1 \%$ & $44.9 \%$ & $0.0 \%$ \\
\hline 11 & 28.81 & 24.20 & 2.39 & NW & 0.327 & $46.8 \%$ & $53.2 \%$ & $0.0 \%$ \\
\hline 12 & 27.15 & 24.20 & 2.32 & NW & 0.327 & $47.0 \%$ & $53.0 \%$ & $0.0 \%$ \\
\hline 13 & 23.55 & 49.77 & 2.85 & SE & 0.357 & $49.0 \%$ & $51.1 \%$ & $0.0 \%$ \\
\hline 14 & 25.15 & 31.16 & 4.01 & SE & 0.390 & $48.5 \%$ & $51.5 \%$ & $0.0 \%$ \\
\hline
\end{tabular}

Table 4. Fate of the mass of water released in every simulation.

The three evaporation patterns show that the evaporation is influenced simultaneously by droplets size and atmospheric conditions. As mentioned above, the droplets lifetime analysis is a suitable method to take into account these two variables in the evaporation process. The variety of the conditions of the 14 cases simulated (Table 3) allows us to analyse the evaporation over a wide range of atmospheric and droplets conditions in an urban environment. The most interesting results of the problem, considering the spread of a contaminant inside the droplets, are the account of mass of water evaporated and the distance that the droplets reach. Both of them are intimately related with the lifetime of the droplets. If the lifetime of the droplets is short, there will be more evaporation, and the droplets that not evaporate drop near the cooling tower.

\section{Temperature and humidity in the area of the cooling tower}

In contrast with previous works of literature about droplets lifetime, where the evaporation occurred under controlled atmospheric conditions, in this work, the droplets can suffer changes in the exterior conditions during the evaporation process, because of the mix between the air released from the cooling tower and the atmospheric air. In the zone of the cooling tower, the atmospheric air has a temperature $T_{a}$ and a relative humidity $H R_{a}$. The air released from the cooling tower is almost saturated. It has a temperature $T_{t}$ and a humidity $H R_{t}$. With the air, a cloud of water droplets arises from the cooling tower. All the droplets leave the tower with a temperature $T_{w}$ (wet bulb temperature of the warm air emitted by the tower), but each droplet has a different diameter $D_{0}$. In the simulations, all droplets released experiment a high change of temperature: they leave the tower with $T_{w}$, but in a very little period of time, they reach a 
lower temperature $T_{w s}$, which they keep during the evaporating process. This temperature $T_{w s}$ depends on the atmospheric conditions (mainly $T_{a}$ and $H R_{a}$ ). Figure 12 corresponds to Case 9 , where $T_{a}=21.4{ }^{\circ} \mathrm{C}$ and $H R_{a}=62 \%$. The air released from the tower $\left(T_{t}=19^{\circ} \mathrm{C}\right.$ and $H R_{t}=$ 99\%) mixes with the atmospheric air and reaches its temperature and humidity very quickly (Fig. 12a). Figure $12 \mathrm{c}$ shows that the droplets arise with $T_{w}=19^{\circ} \mathrm{C}$, and their temperature decreases immediately until $T_{w s}=17.45^{\circ} \mathrm{C}$. As expected, during most of the evaporation process, the conditions remain constant: air at $T_{a}$ and $H R_{a}$, and droplets at $T_{w s}$.

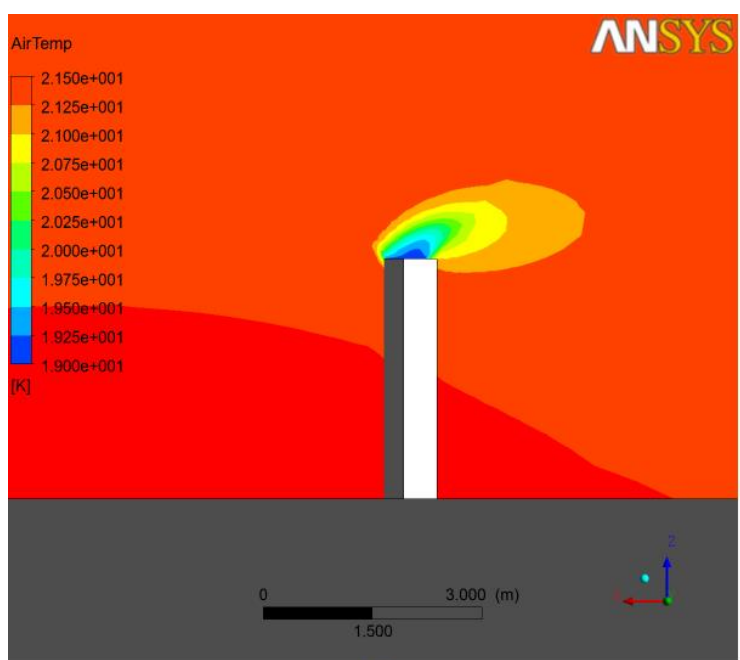

a)

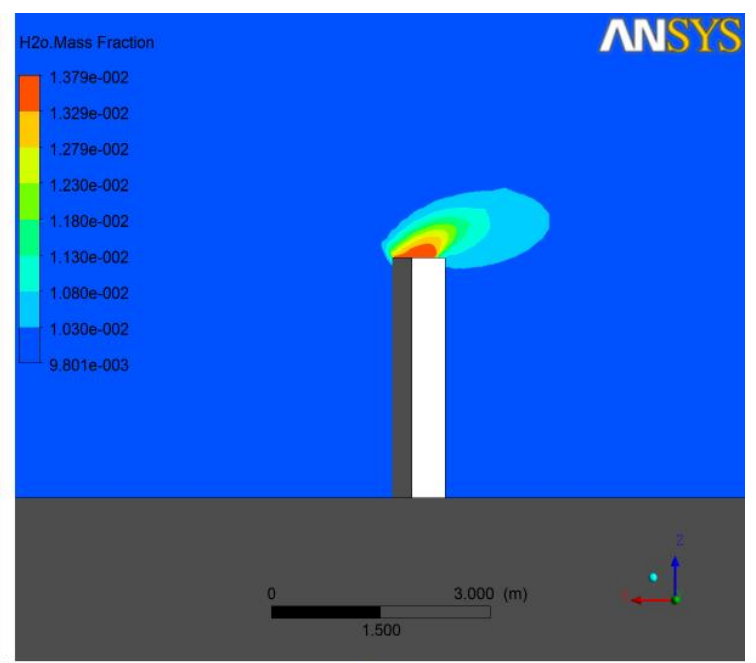

b)

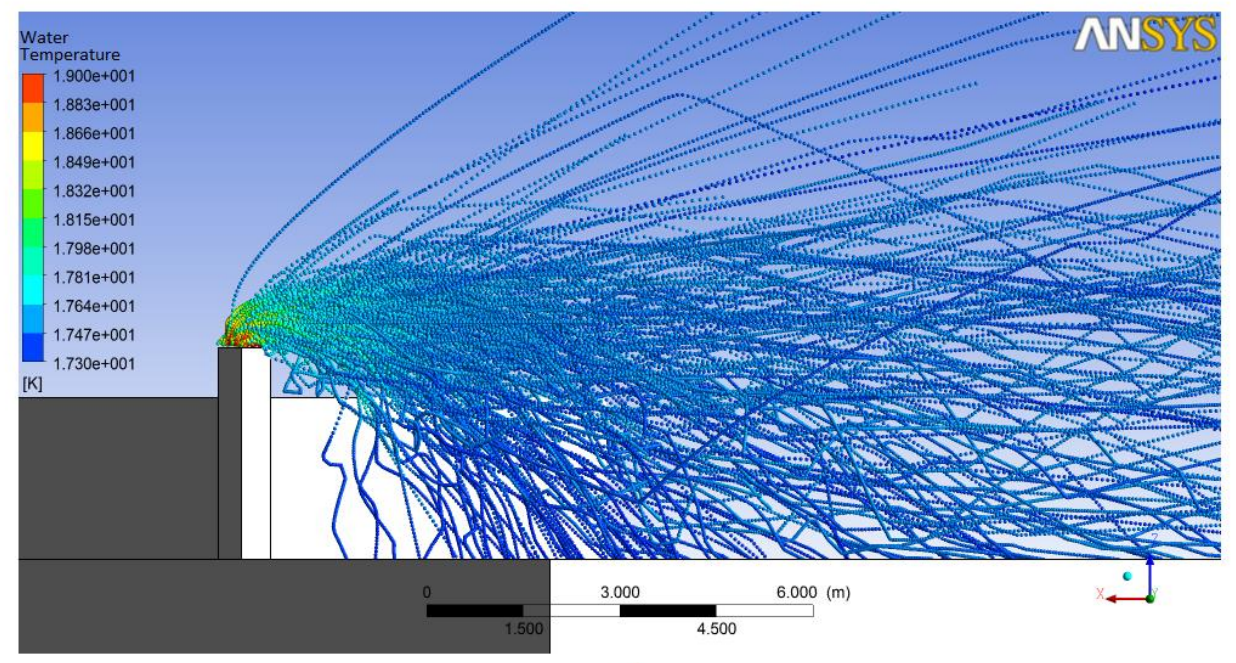

c)

Figure 12. a) Air temperature (a), specific humidity (b) and droplets temperature (c) in the area of the cooling tower in Case 9. The water and air released from the cooling tower suffer a short warming until the adaption to the atmospheric conditions.

\subsection{Model for the droplets lifetime}

The lifetime of the particles provides useful information about the area affected by the cooling tower. In a supposed outbreak of Legionella from the cooling tower, it would be desirable that droplets evaporate before reach the ground. That occurs when the lifetime of the droplet is less than the time that the particle would last to impact on the ground. That time of impact can be estimated as a function of variables like the size of the particle, the height of the cooling tower and the atmospheric conditions. Holterman developed an expression for calculating the lifetime 
of a droplet under steady evaporation conditions [10]. It would be interesting to test the validity of Holterman's equation for the cloud of droplets of different sizes emitted by a cooling tower. It would provide a quick method for estimating the area affected by the cooling tower. The numerical droplet lifetimes obtained in the simulations are compared with the analytical droplet lifetimes obtained by means of the Holterman's equation [10] (explained below), in order to study the validity of that equation for estimating the lifetime of the droplets released from cooling towers located in urban environment.

\section{Holterman's equation of a droplet lifetime}

Williamson and Threadgill (1974) described the rate of decrease of the diameter of a spherical drop due to evaporation as:

$$
\frac{d D_{p}}{d t}=\frac{-4 M_{p} D_{v, f}}{D_{p} \rho_{p} R T_{f}} \Delta p\left(1+0.276 R e_{p}^{1 / 2} S c_{p}{ }^{1 / 3}\right),
$$

where $D_{p}$ is the diameter of the droplet, $M_{p}$ and $\rho_{p}$ are the molecular weight and the density of the liquid, respectively (water in this case), $R$ is the ideal gas constant (air), $T_{f}$ is the absolute temperature of the air in the saturated film of the particle, $D_{v, f}$ is the diffusion coefficient (for vapour molecules in this case) in the saturated film and $\Delta p$ is the difference between the vapour pressure in the film of the droplet and that in the ambient atmosphere. This variable can be regarded as the driving force of the evaporation, and it has a significant influence on the evaporation rate. In Eq. (22), Reynolds number is defined as:

$$
R e_{p}=\frac{\rho D_{p} v}{\mu}
$$

being $\rho$ the density of the air in the film of the droplet, $\mu$ the dynamical viscosity of the air in the film and $v$ the velocity of the drop relative to the surrounding air. Lastly, $S c_{p}$ is the Schmidt's number, defined as:

$$
S c_{p}=\frac{\mu}{\rho D_{v, f}}
$$

Holterman [10] worked on Eq.(22), assuming that the droplet are falling down at sedimentary velocity (without horizontal velocity relative to the air), with the wet bulb temperature of the air, he obtained the analytical lifetime of a droplet with initial diameter $D_{0}$ :

$$
t_{\text {life }}=\frac{2}{q_{1}^{2} q_{0} \Delta T}\left[q_{1}\left(D_{0}\right)-\ln \left(1+q_{1} D_{0}\right)\right]
$$

where $\Delta T$ is the difference of temperature between dry-bulb and wet-bulb temperature of the atmospheric air. The values of the constants $q_{0}$ and $q_{1}$ are:

$$
\begin{aligned}
& q_{0}=\frac{8 \gamma M_{p} D_{v, f}}{\rho_{p} R T_{f}}\left(1+b s_{0}\right), \\
& q_{1}=\frac{b r_{0}}{1+b s_{0}}
\end{aligned}
$$

with $\gamma=67 \mathrm{~Pa} / \mathrm{K}, r_{0}=64.65 \mathrm{~s}^{-0.5}$ and $s_{0}=-1.117 \cdot 10^{-3} \mathrm{~m} \cdot \mathrm{s}^{-0.5}$, whereas the value of $b$ is: 


$$
b=0.276\left(\frac{\rho}{\mu D_{v, f^{2}}}\right)^{1 / 6}
$$

\section{Validity of the Holterman's equation in the described problem}

The way to test the agreement between the droplet lifetime obtained by our numerical model and the droplet lifetime obtained by means of the Holterman's equation (25) is by means of the comparison of the values of the constants $q_{0}$ and $q_{1}$ obtained through two different methods: by means of the analytical expressions Eq. (26) and Eq. (27) defined by Holterman [10] (which can be regarded as theoretical values), and by means of the numerical results obtained from the simulations, through a mathematical fitting (which can be regarded as numerical values). The way to calculate the numerical values of the constants in each simulation is by means of a least squares fitting. The numerical simulation is able to give the lifetime $t_{\text {life }}$ and the initial diameter $D_{0}$ of every one of the droplets that evaporates completely. Each simulation has a different $\Delta T$. The problem is to find the values of $q_{0}$ and $q_{1}$ that optimize the fitting of the Eq. (25) to the numerical values of $t_{\text {life }}$ and $D_{0}$. Figure 13 shows the numerical values for each diameter $D_{0}$ (red crosses) and the fitting function (black line) for Case 9. Note that Eq. (25) reproduces the numerical data with an excellent agreement $\left(R^{2}=0.9994\right)$.

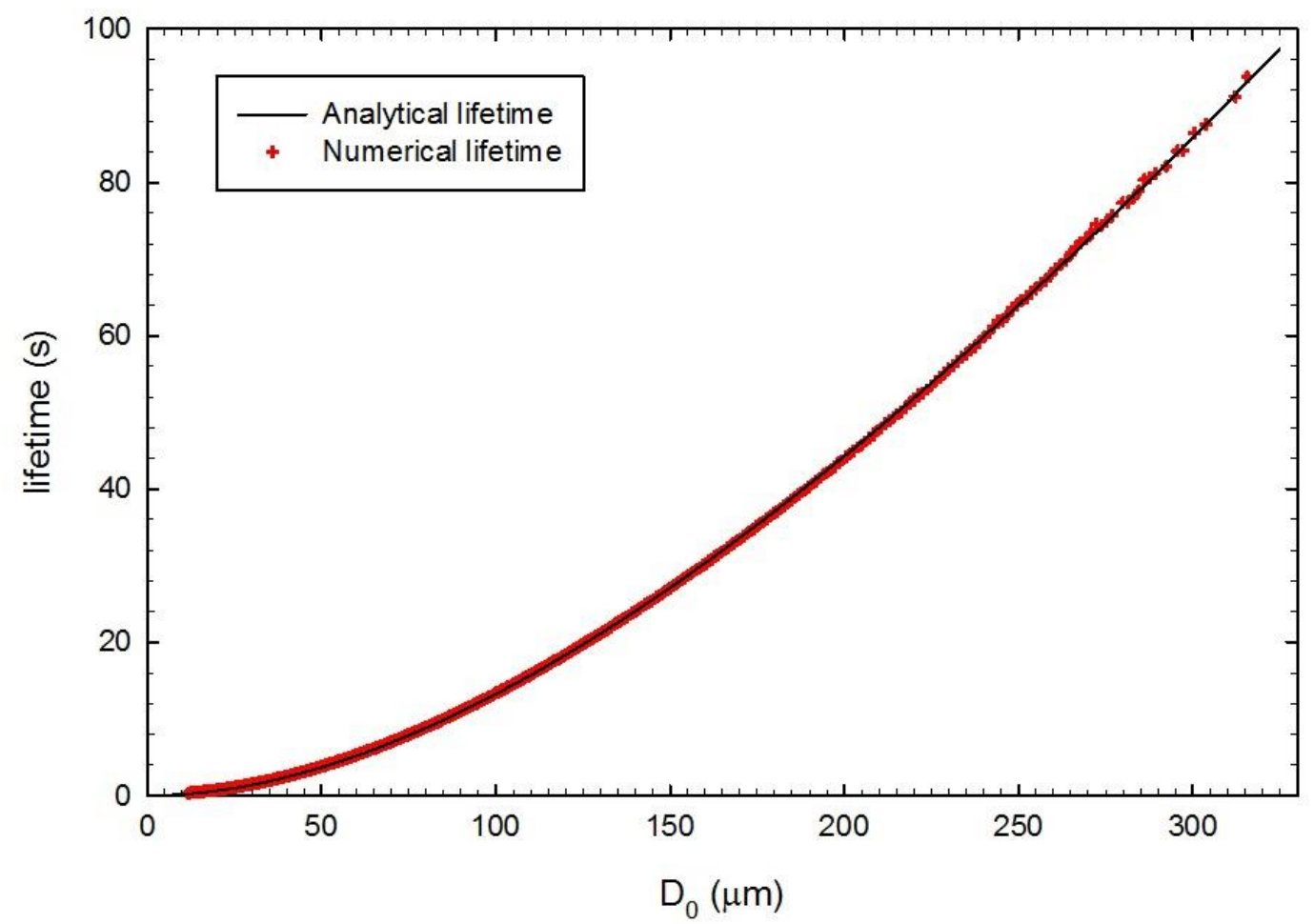

Figure 13. Comparison between the numerical values of lifetime and the analytical expression for the lifetime proposed in this work (Eq. (25)) for Case 9.

Table 5 shows the atmospheric conditions in each simulation, as well as the constants $q_{0}$ and $q_{1}$ calculated numerically, along with their theoretical values, calculated with Eqs. (26-27). The theoretical values of $q_{0}$ and $q_{1}$ only depend on the temperature of the droplet (see Eqs. (2627)), because the saturated air in the film around the droplet has the same temperature than the droplet. 


\begin{tabular}{|c|c|c|c|c|c|c|}
\hline No. & $\begin{array}{c}\mathrm{T}_{\mathrm{a}} \\
(\mathrm{o} \mathrm{C})\end{array}$ & $\begin{array}{c}\mathrm{HR}_{\mathrm{a}} \\
(\%)\end{array}$ & $\begin{array}{c}\mathrm{q}_{0} \\
\text { Numerical } \\
\left(\mu \cdot \mathrm{m}^{2} /(\mathrm{s} \cdot \mathrm{K})\right)\end{array}$ & $\begin{array}{c}\mathrm{q}_{0} \\
\text { Eq. }(26) \\
\left(\mu \cdot \mathrm{m}^{2} /(\mathrm{s} \cdot \mathrm{K})\right)\end{array}$ & $\begin{array}{c}\mathrm{q}_{1} \\
\text { Numerical } \\
\left(\mu \mathrm{m}^{-1}\right)\end{array}$ & $\begin{array}{c}\mathrm{q}_{1} \\
\text { Eq. }(27) \\
\left(\mu \mathrm{m}^{-1}\right)\end{array}$ \\
\hline 1 & 23.85 & 65.50 & $\mathbf{9 4 . 3 9}$ & $\mathbf{8 9 . 5 2}$ & $\mathbf{0 . 0 0 3 8}$ & $\mathbf{0 . 0 0 4 2}$ \\
\hline 2 & 17.45 & 40.50 & $\mathbf{9 8 . 9 9}$ & $\mathbf{8 7 . 1 1}$ & $\mathbf{0 . 0 0 3 9}$ & $\mathbf{0 . 0 0 4 3}$ \\
\hline 3 & 10.70 & 68.80 & - & - & - & - \\
\hline 4 & 15.65 & 44.00 & $\mathbf{9 2 . 9 7}$ & $\mathbf{8 6 . 7 9}$ & $\mathbf{0 . 0 0 4 6}$ & $\mathbf{0 . 0 0 4 3}$ \\
\hline 5 & 13.85 & 49.50 & $\mathbf{9 5 . 0 5}$ & $\mathbf{8 6 . 4 9}$ & $\mathbf{0 . 0 0 4 3}$ & $\mathbf{0 . 0 0 4 4}$ \\
\hline 6 & 9.16 & 35.60 & - & - & - & - \\
\hline 7 & 17.75 & 62.50 & $\mathbf{9 2 . 6 5}$ & $\mathbf{8 7 . 8 5}$ & $\mathbf{0 . 0 0 4 3}$ & $\mathbf{0 . 0 0 4 3}$ \\
\hline 8 & 17.45 & 63.70 & $\mathbf{9 0 . 2 8}$ & $\mathbf{8 7 . 8 2}$ & $\mathbf{0 . 0 0 4 6}$ & $\mathbf{0 . 0 0 4 3}$ \\
\hline 9 & 21.43 & 61.80 & $\mathbf{9 6 . 7 8}$ & $\mathbf{8 8 . 7 6}$ & $\mathbf{0 . 0 0 4 0}$ & $\mathbf{0 . 0 0 4 2}$ \\
\hline 10 & 20.20 & 67.00 & $\mathbf{8 0 . 0 4}$ & $\mathbf{8 8 . 8 0}$ & $\mathbf{0 . 0 0 3 4}$ & $\mathbf{0 . 0 0 4 2}$ \\
\hline 11 & 28.81 & 28.00 & $\mathbf{9 4 . 7 2}$ & $\mathbf{8 8 . 8 5}$ & $\mathbf{0 . 0 0 5 6}$ & $\mathbf{0 . 0 0 4 2}$ \\
\hline 12 & 27.15 & 26.70 & $\mathbf{8 8 . 6 1}$ & $\mathbf{8 8 . 7 3}$ & $\mathbf{0 . 0 0 5 1}$ & $\mathbf{0 . 0 0 4 2}$ \\
\hline 13 & 23.55 & 51.00 & $\mathbf{9 7 . 2 7}$ & $\mathbf{8 8 . 9 1}$ & $\mathbf{0 . 0 0 4 1}$ & $\mathbf{0 . 0 0 4 2}$ \\
\hline 14 & 25.15 & 31.00 & $\mathbf{9 6 . 3 9}$ & $\mathbf{8 8 . 5 0}$ & $\mathbf{0 . 0 0 4 2}$ & $\mathbf{0 . 0 0 4 2}$ \\
\hline
\end{tabular}

Table 5. Values of the constants $\mathrm{q}_{0}$ and $\mathrm{q}_{1}$ calculated by means of two different methods: through a mathematical fitting of the numerical results to the Eq. (25) and by means of Eq. (26) an Eq. (27), respectively.

Table 5 shows a clear agreement between the numerical and the theoretical values obtained for $q_{0}$ and $q_{1}$. The numerical $q_{0}$ is only slightly higher than the theoretical one. Note that it is not possible to calculate the value of the constants of Cases 3 and 6 , because they do not have any evaporation. In our model, the evaporation of the droplets starts when they reach the vaporization temperature $\left(T_{v}=10.85^{\circ} \mathrm{C}\right)$; below that temperature, droplets only experiment inert heating. In the Cases 3 and 6, the atmospheric conditions do not allow droplets to reach temperatures over $T_{v}$. So, when the temperature of the atmospheric air is less than $T_{v}=$ $10.85^{\circ} \mathrm{C}$, the droplets could not reach the minimum temperature needed for evaporation. In that case droplets do not evaporate and they remain in the air until they fall down onto the floor (their lifetime is infinite).

\subsection{Influence of ambient and droplets conditions in the lifetime of droplets}

Once the analytical model for prediction of the lifetime of droplets has been explained and validated, an analysis of the effects of the ambient and droplets conditions on the droplets lifetime can be conducted, for urban environments. Analysing Eq. (25) it may deducted that droplets lifetime is a function of three variables: diameter of the droplet $D_{0}$, air temperature $T_{a}$ and relative humidity of the atmospheric air $H R_{a}$.

As Eq. (25) shows, droplets lifetime increases when the diameter of the droplets increases (see Fig. 14). Whit high diameters, the influence of the term $\ln \left(1+q_{1} D_{0}\right)$ in Eq. (25) is weaker, and the relation between the lifetime and the diameter could be considered as lineal. 


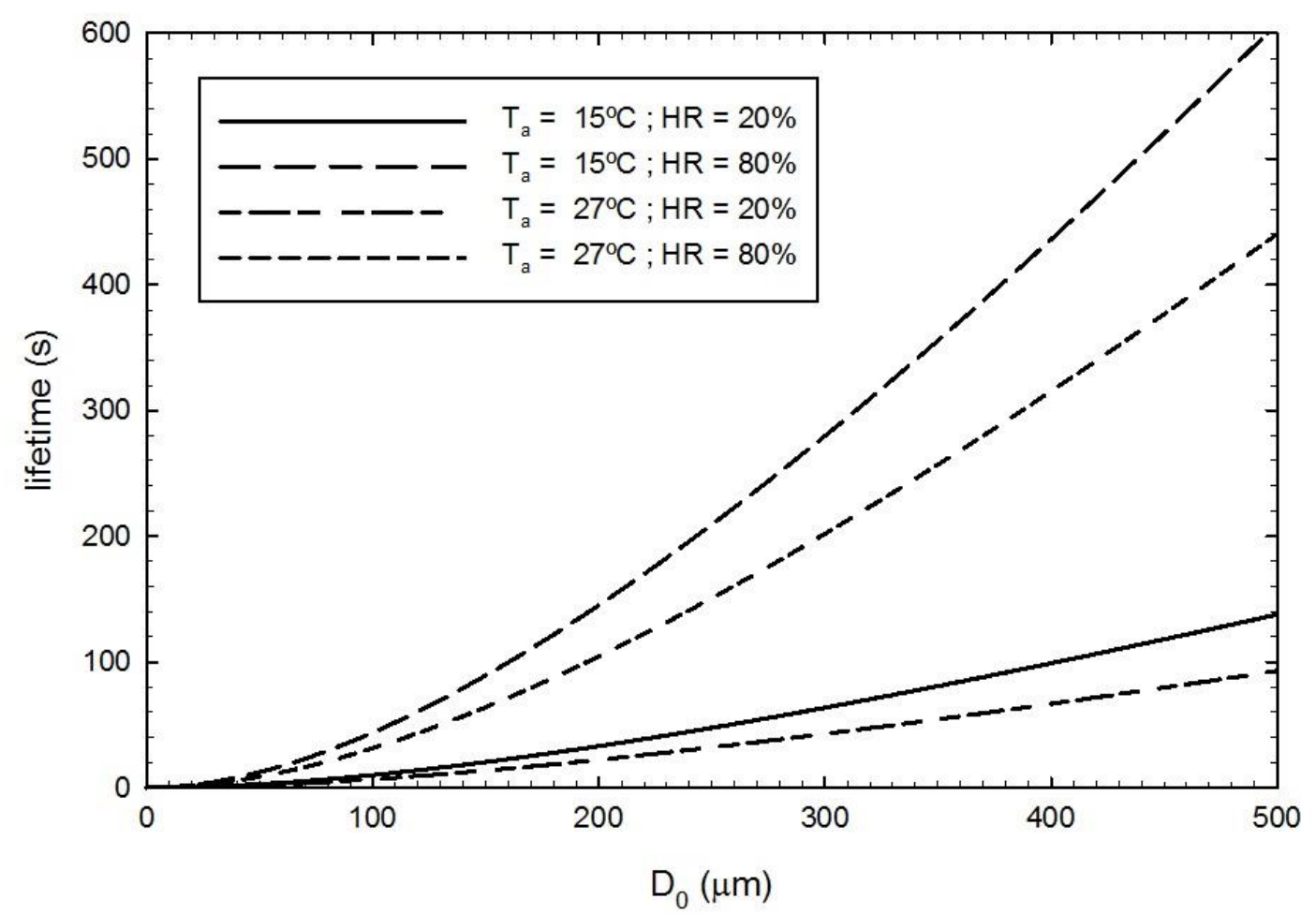

Figure 14. Droplets lifetime variation with droplets diameter under different atmospheric conditions

Droplets lifetime is inversed proportional to $\Delta T$; this means that the droplets lifetime is higher when the vapour pressure difference between the atmospheric air and the saturated film of air around the droplet is low. Figure 15 shows the relation of droplets lifetime and $T_{a}$ under different diameters and relative humidity of the air (in 15a $H R_{a}=20 \%$, in $15 \mathrm{~b}$ a $H R_{a}=50 \%$ and in $\left.15 \mathrm{c} H R_{a}=90 \%\right)$. The increase of air temperature produces a higher vapour pressure difference, decreasing the lifetime of the droplets. However, the atmospheric air relative humidity has more influence in the droplets lifetime than the air temperature. With high relative humidity, the air is near the saturation, the difference of vapour pressure is low, and the droplets lifetime is high. When the relative humidity is low, there is more evaporation, and the droplets lifetime is short. 


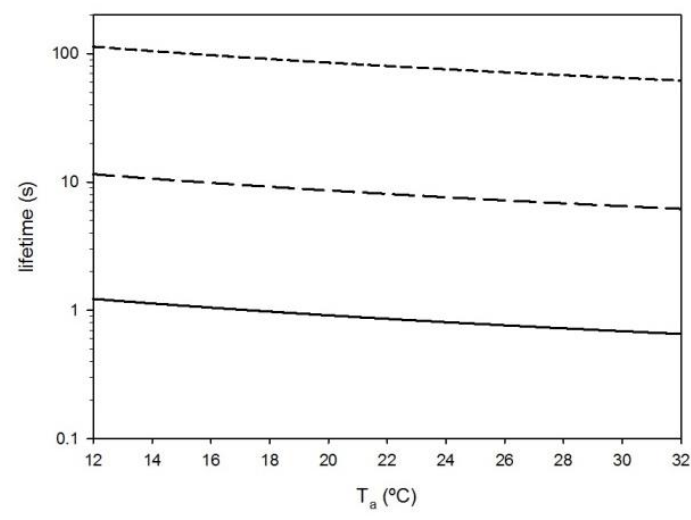

a)

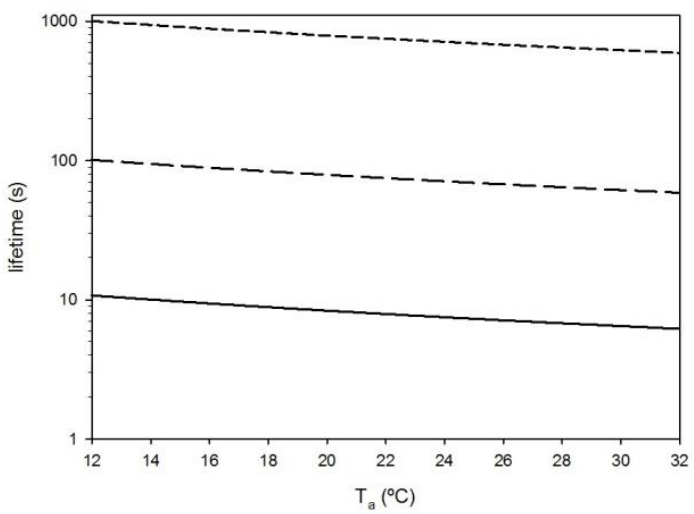

c)

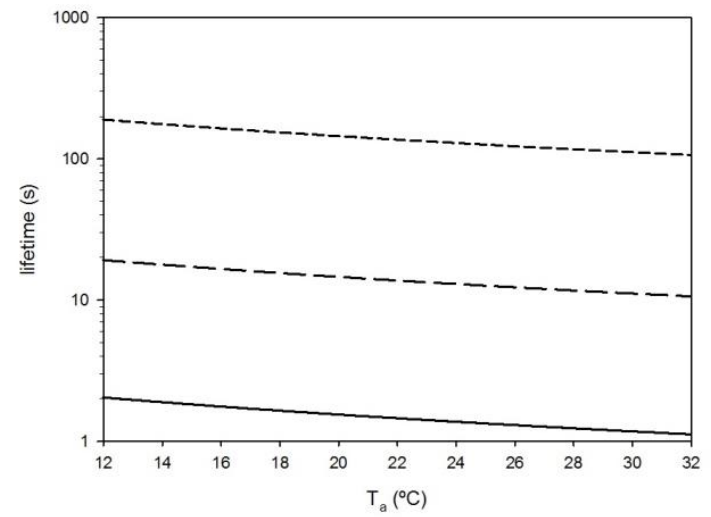

b)

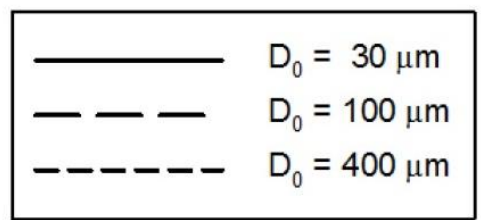

Figure 15. Droplets lifetime variation with the air temperature under different diameters and relative humidity. a) HR $=20 \%$. b) $\mathrm{HR}=50 \%$. c) $\mathrm{HR}=90 \%$.

In conclusion, the droplets lifetime (Eq. (25)) depends on the atmospheric air conditions (air temperature and relative humidity), and the droplets size $D_{0}$. On the one hand, droplets lifetime increases with droplets size (see Fig. 15). On the other hand, droplets lifetime is inversed proportional to the vapour pressure difference, which is favoured by high atmospheric temperature and low relative humidity. In a supposed outbreak of Legionella, with origin in the water of a cooling tower, the less dangerous scene would be when the droplets evaporated before impact on the ground; this situation is produced when the droplets lifetime is shorter than the time necessary to drop from the cooling tower to the ground. A short droplet lifetime is favoured by little size of droplets, high atmospheric temperature and low relative humidity.

\section{Conclusions}

A numerical modelling capable to estimate drift, droplet evaporation and deposition in a mechanical cooling tower located in an urban area is developed. An Eulerian-Lagragian model was employed for the simulation. The continuous phase (wet air) is modelled by means of the simplified RANS steady equations, while the water droplets are considered as discrete phase.

Experimental results from the real mechanical cooling tower were employed to validate the numerical results in terms of total deposition on the floor. Sensitive paper technique is used to obtain the experimental deposition on 20 points of the floor; the biharmonic interpolation is used for obtaining the deposition on the rest of points of the floor. A total of 14 cases are considered. The agreement between experimental and numerical data is good. 
A study of the droplet lifetime is carried out from the numerical results obtained in the 14 simulations. The numerical droplet lifetimes obtained in the simulations were compared with the analytical droplets lifetimes obtained from Holterman's equation. Although Holterman's model was developed for estimating the lifetime of droplets falling down at sedimentary velocity under controlled air conditions, the comparison between numerical and analytical droplet lifetimes showed that Holterman's equation is able to predict the lifetime of the droplets released from cooling towers located in urban environments.

One of the problems of cooling tower systems is the spread of bacteria, such as Legionella, to the atmosphere inside the droplets emitted, causing risk of disease to the people. An analysis of the influence of atmospheric and droplet conditions in the evaporation process was carried out. Droplets lifetime depend on the atmospheric temperature, relative humidity of the air and droplet size. The less dangerous situation is when the droplets lifetime is shorter than the time necessary to reach the ground. A short droplet lifetime is favoured by high atmospheric temperature, low relative humidity and little size of the droplet.

Acknowledgments

This research is sponsored by the Spanish Government, through the Projects No. ENE201348696-C2-2-R and ENE2013-48696-C2-1-R, including FEDER (European Union).

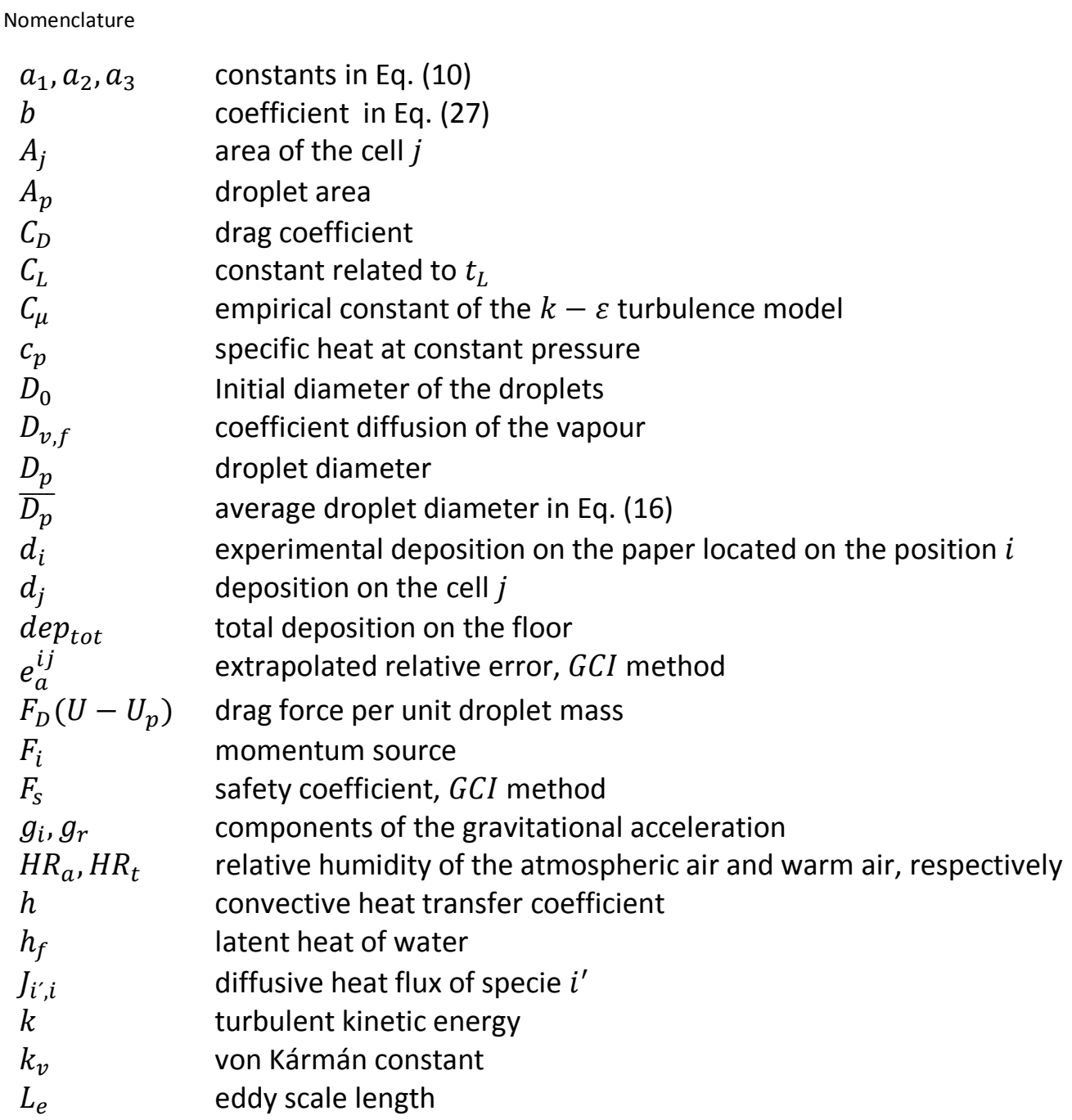




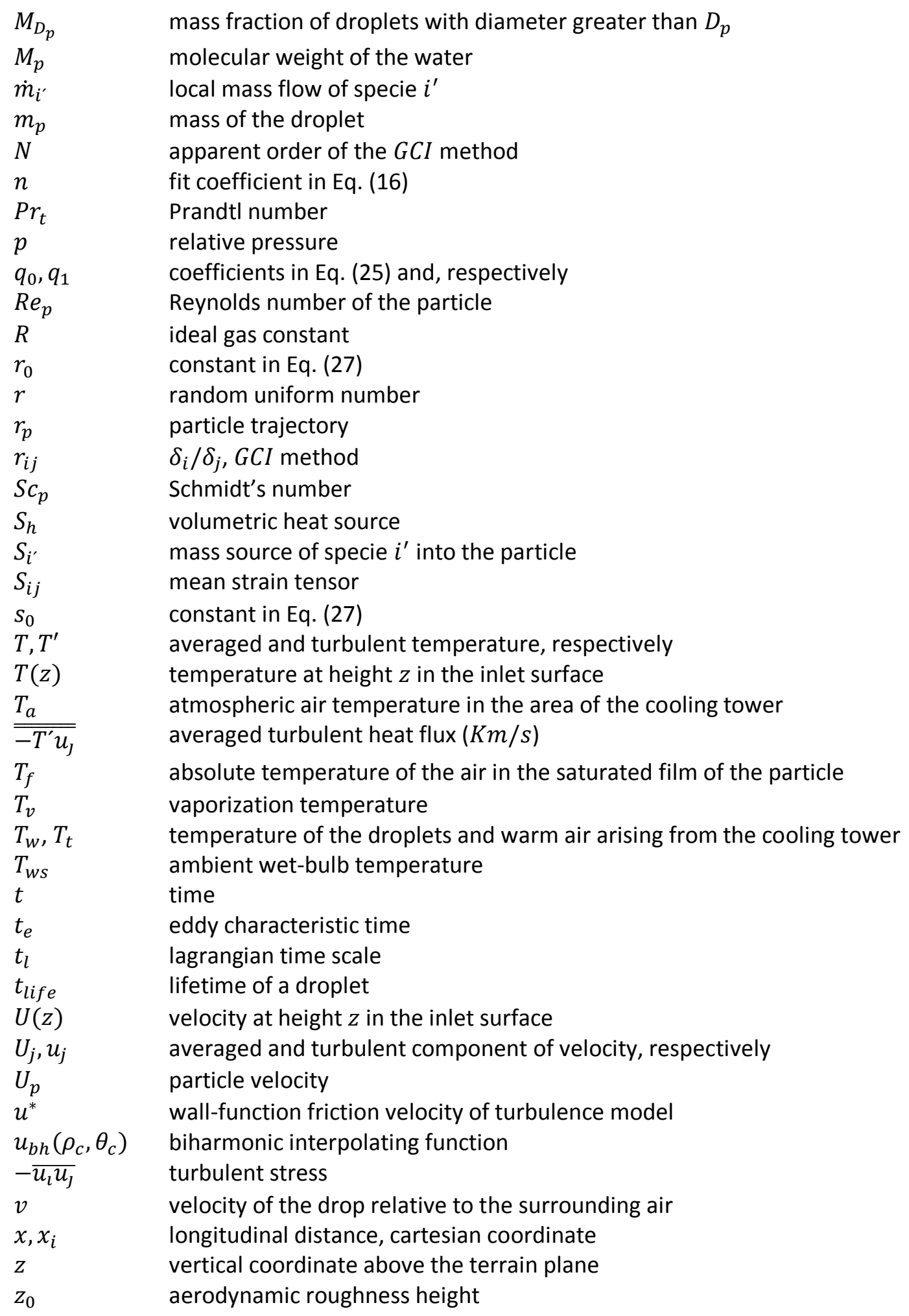

\section{Greek symbols}

$\begin{array}{ll}\alpha & \text { vertical gradient of temperature } \\ \beta & \text { constant in Eq. (15) } \\ \gamma & \text { constant in Eq. (26) } \\ \Delta p & \text { vapour pressure difference between the droplet and the film around it } \\ \Delta T & \text { difference between dry-bulb and wet-bulb temperature } \\ \delta_{1}, \delta_{2}, \delta_{3} & \text { typical cell sizes }\end{array}$




$\begin{array}{ll}\delta_{i j} & \text { Krönecker delta } \\ \varepsilon & \text { dissipation rate of } k \\ \theta_{c} & \text { angular coordinate in Eq. (19) } \\ \kappa & \text { thermal conductivity } \\ \mu & \text { viscosity of the gas } \\ v_{t} & \text { turbulent kinematic viscosity of the gas, } v_{t}=C_{\mu} k^{2} / \varepsilon \\ \rho & \text { density of the continuous phase } \\ \rho_{c} & \text { radius coordinate in Eq.(19) } \\ \rho_{p} & \text { density of the droplet } \\ \tau & \text { particle relaxation time } \\ \phi & \text { dimensionless mass flow on the floor } \\ \varphi_{j} & \text { key variable, } G C I \text { method } \\ \omega, \omega_{a} & \text { specific humidity, ambient specific temperature }\end{array}$

\section{Abbreviations}
$A B L$
$C F D$
Atmospheric Boundary Layer
GCI Computational Fluid Dynamics
RANS Grid Convergence Index
Reynolds Averaged Navier-Stokes equations

References

[1] R. Isozumi, Y. Ito, I. Ito, M. Osawa, T. Hirai, S. Takakura, Y. Linuma, S. Ichiyama, K. Tateda, K. Yamaguchi, M. Mishima, An outbreak of Legionella pneumonia originating from a cooling tower, Scandinavian Journal of Infectious Diseases 37 (10) (2005) 709-711.

[2] K. Takata, K. Nasu, H. Yoshikawa, Prediction of the plume from a cooling tower, Cooling Tower Institute Annual Conference, Houston, 1996.

[3] A. Riddle, D. Carruthers, A. Sharpe, C. McHugh, J. Stocker, Comparisons between FLUENT and ADMS for atmospheric dispersion modeling, Atmospheric Environment 38 (2004) 10291034.

[4] M. Lucas, P. Martínez, J. Ruiz, A. Kaiser, A. Viedma, On the influence of psychometric ambient conditions on cooling tower drift deposition, International Journal of Heat and Mass Transfer 53 (2010) 594-604.

[5] RN. Meroney, CFD prediction of cooling tower drift, Journal of Wind Engineering and Industrial Aerodynamics 94 (2006) 463-490

[6] Y. Lu, H. Gurgenci, Z. Guan, S. He, The influence of windbreak wall orientation on the cooling performance of small natural draft dry cooling towers, International Journal of Heat and Mass Transfer 79 (2014) 1059-1069

[7] AJ. Consuegro, A. Kaiser, B. Zamora, F. Sánchez, M. Lucas, M. Hernández, Numerical modeling of the drift and deposition of droplets emitted by mechanical cooling towers on buildings and its experimental validation, Building and Environment 78 (2014) 53-67.

[8] D. Hu, H. Wu, Z. Liu, Effect of liquid-vapor interface area on the evaporation rate of small sessile droplets, International Journal of Thermal Sciences 84 (2014) 300-308. 
[9] F. Girard, M. Antoni, S. Faure, A. Steinchen, Influence of heating temperature and relative humidity in the evaporation of pinned droplets, Colloids and Surfaces A: Physicochem. Eng. Aspects 323 (2008) 36-49.

[10] HJ. Holterman, Kinetics and evaporation of water drops in air, IMAG, Wagenningen, 2003, pp. 1-67.

[11] J. Ruíz, A. Kaiser, M. Ballesta, A. Gil, M. Lucas, Experimental measurement of cooling tower emissions using image processing of sensitive papers. Atmospheric Environment 69 (2013) 170-181.

[12] S. Morsi, A. Alexander, An investigation of particle trajectory in two-phase flow systems, Journal of Fluid Mechanics 55 (2) (1972) 193-208.

[13] P. Richards, R. Hoxey, Appropiate boundary conditions for computational wind engineering models using $k-\varepsilon$ turbulence model. Journal of Wind Engineering and Industrial Aerodynamics $46 \& 47$ (1993) 145-153.

[14] PJ. Roache, Quantification of uncertainty in computational fluid dynamics, Annual Review of Fluid Mechanics 29 (1997) 123-160.

[15] D. Sandwell, Biharmonic spline interpolation of Geos-3 and Seasar altimeter data, Geophysical Research Letters 14 (2) (1987) 139-142.

[16] I. Briggs, Machine contouring using minimum curvature, Geophysics 39 (1974) 39-48.

[17] X. Deng, Z. Tang, Moving surface spline interpolation based on Green's function, MathGeosci 43 (2011) 663-680. 